\title{
La confirmación obligatoria de sentencias declarativas de nulidad matrimonial. Cuestiones debatidas en la Comisión para la reforma del Código de Derecho Canónico [1977-1981]
}

The required confirmation for sentences declaring nullity of marriages. Issues debated in the Commission for the Revision of the Code of Canon Law [1977-1981]

\begin{abstract}
In the last few months, especially since last Synod (October 2014), the question regarding the necessity of the confirmation of the sentence when declaring the invalidity marriage has become an area of debate. This article brings together the arguments surrounding this debate during the compilation of the Codex of 1983 - a debate which extended until right up to the final moments of the codification. The opinions of the contributors to the Code were varied and the debate was long and profound. Thirty years later it appears that the problems that were debated then continue to exist today.
\end{abstract}

\section{Keywords}

Marriage processes, Nullity of the marriage confirmation, Revision Codex of Canon Law.

\section{La reforma del Derecho Procesal. La búsqueda permanente de la simplificación}

"Una palabra ha brotado espontánea y uniforme de los labios o de la pluma de todos aquellos que de una manera o de otra se han ocupado del futuro proceso 
canónico: simplificación"'. Estas palabras que Xavier Ochoa pronunció en unas Jornadas sobre Derecho Procesal Canónico celebradas en Salamanca a finales de los setenta del pasado siglo, sintetizaban la gran preocupación existente entre aquellos que tuvieron la misión de reformar la legislación procesal de la Iglesia que no era otra que la de facilitar los procedimientos judiciales canónicos, especialmente los de nulidad matrimonial.

Han transcurrido ya más de treinta años desde la entrada en vigor del Código promulgado en 1983 y todavía el problema de la simplificación de los procesos matrimoniales sigue siendo principal. Carmen Peña señalaba en 2010 una serie de temas que, aunque planteados durante la codificación, no habían encontrado solución en la práctica de los tribunales eclesiásticos, ni siquiera tras la aplicación de la Instrucción Dignitas Connubi ${ }^{2}$. Así las cosas en varias ocasiones desde el inicio del pontificado del Papa Francisco se ha venido hablando de una reforma del proceso canónico de nulidad matrimonial y uno de los aspectos en los que se ha incidido es en la necesidad o no de mantener la exigencia de que sean siempre necesarias dos sentencias conformes declarativas de nulidad para que los cónyuges puedan considerar su matrimonio efectivamente nulo y en su caso contraer un nuevo matrimonio ${ }^{3}$.

Hace unos años, en 2004, preparando mi tesis doctoral, tuve oportunidad de estudiar a fondo el c. 1682 y muy especialmente el tratamiento del tema de la obligatoriedad de la doble sentencia conforme durante el proceso codificador. Entonces me llamó la atención el que entre las últimas seis cuestiones que fueron objeto de debate en la Congregatio Plenaria que estudiaría en octubre 1981 el borrador final del Código, se incluyera la de la apelación obligatoria, aun cuando ya había quedado establecida la fórmula de la trasmisión automática de las actas y del procedimiento abreviado que se había venido ya ensayando desde la entrada en vigor del M.P. Causas matrimoniales ${ }^{4}$.

1 J. Ochoa, Cuestiones procesales “de iure condendo” en materia procesal, en: “Curso de Derecho matrimonial y procesal canónico para profesionales del foro” vol. 3, Salamanca 1978, p. 223.

C. Peña, Derecho a una justicia eclesial rápida: sugerencias de iure condendo para agilizar los proceso canónicos de nulidad, REDC 67 (2010) 741-771.

3 Constituida en agosto de 2014 una Comisión para el estudio de estos temas, ya durante el Sínodo se ha hablado en varias ocasiones de éste como uno de los aspectos a revisar.

4 Mi tesis doctoral "El proceso de confirmación de sentencias declarativas de nulidad matrimonial en los tribunales eclesiásticos”, dirigida por el Prof. Dr. Bogarín Díaz, no ha sido publicada. Sin embargo puede consultarse a través del repositorio "Arias Montano" de la Biblioteca Universitaria de Huelva, en el enlace http://rabida.uhu.es/dspace/handle/10272/2628 (25.06.2015). 
Creo que es este un buen momento para repasar algunas actuaciones de la Comisión encargada de la reforma del Código de Derecho Canónico con relación a esta cuestión. En concreto estudiar las distintas redacciones, del que al final sería el c. 1682 del Código promulgado por Juan Pablo II y muy especialmente los documentos que fueron objeto de consideración en la última de las reuniones en las que se trató el tema, la que tuvo lugar en octubre de $1981^{5}$. Fueron muchos y muy razonables los argumentos que en aquellas reuniones se expusieron por parte de personas que conocían bien la teoría y la práctica de los tribunales eclesiásticos, en pro y en contra de la cuestión que subyacía en este precepto que no es otra que la obligación de la revisión de todas las sentencias de nulidad, o lo que viene a ser lo mismo la exigencia de la "doble conforme".

\section{La reforma de la apelación en las causas de nulidad}

Las tareas de revisión del Código como es sabido se organizaron y se distribuyeron en cinco fases: Una fase de redacción, desde 1966 al 1976, que concluyó con la redacción de un primer borrador sobre el que iniciar los trabajos; siguió desde 1977 a 1980 una fase consultiva, durante la cual diversas instituciones fueron consultadas sobre el borrador presentado y que concluye con la revisión sobre el primitivo texto, realizada teniendo en cuenta las aportaciones de los organismos consultados; a continuación fue la fase deliberativa, durante la que se discutieron las diversas propuestas recogidas durante la fase anterior y que tuvo lugar durante 1981 para concluir con la con la fase legislativa, en la cual y tras una última revisión realizada por el propio legislador en 1982, una vez

5 Después de aquella reunión, el Santo Padre revisó, con el auxilio de una comisión de obispos y otra formada por expertos, el texto del borrador finalmente aprobado pero puede colegirse que por lo que se refiere al c. 1682, no hubo variación entre el texto finalmente promulgado y el que contenía el borrador final, como se ha señalado "Non conosciamo il tenore delle reunioni della commisine di Vescovi, mentre per quella di esperti possiamo basarsi sulle informazioni fornite da Betti. Quest'ultimo non riferisce nulla di rilevante, a propósito né della riunione del 28 settembre 1982, né della riunione degli esperti con il Papa del 30 settembre 1982 per l'esame dei canoni 1501-1776 (quindi comprendenti anche il nostro). In ogni caso, solo confrontando lo Schema CIC/1982, cd. Novissimum, e il CIC/1983 possiamo dedurre le variazioni apportate dallo stesso Legislatore. Per quanto siguarda el nostro argomento, dunque, si constata che il testo del c. 1682 risulta invariato nel CIC promulgato". B. Ugge, La fase preliminare/abbreviata del proceso di nullità del matrimonio in secondo grado di giudizio a norma del can. 1682, 2, Roma 2003, p. 91. 
concluidos los trabajos de las Comisiones, se promulgaría el nuevo Código de Derecho Canónico ${ }^{6}$.

La redacción del canon 1682, en el que se regula la trasmisión obligatoria a segunda instancia de las sentencias declarativas de nulidad, prácticamente no tuvo variaciones desde el borrador que en 1979 fue sometido a deliberación, pero ello no significa que no hubiera discusión en torno a lo que este precepto establece, especialmente por lo que se refiere a la cuestión de fondo ¿es necesaria siempre y en todo caso la revisión de las sentencias declarativas de nulidad? Desde que Benedicto XIV estableciera la apelación obligatoria del defensor del vínculo a las sentencias pro nullitate, así se ha venido entendiendo pero sin duda una medida establecida en el contexto del s. XVIII merecía un análisis de quienes llevaron a cabo el proceso de reforma del Derecho de la Iglesia en el s. XX. Este análisis se hizo y creo que merece la pena recordarlo en este momento.

\section{A) Fase de preparación del documento para deliberar}

a) Elaboración del primer borrador (1966-1976)

El 28 de mayo de 1963, Juan XXIII constituyó la Pontificia Commisio Codici Iuris Canonici recognoscendo 7 . Su sucesor Pablo VI, en abril de 1964 creó, con el fin de asesorar a la Comisión de Cardenales, un Colegio de Consultores que celebró sesión plenaria por primera vez el 6 de mayo de 1965 bajo la presidencia de Mons. Felici. Esta asamblea concluyó con la redacción de un texto sobre las cuestiones fundamentales que deberían marcar el camino de la reforma. Tras esta segunda reunión el trabajo se dividió. Por un lado, se crearon grupos de estudios o subcomisiones a las que se les encomendó el análisis de temas concretos. Por otro, una Comisión central de Consultores preparaba un documento, que titularían Principia quae Codicis recognitione dirigant el cual primero fue revisado por los miembros de la Comisión cardenalicia, y más tarde sometido a la aprobación del Sínodo de los Obispos que se celebraba en Roma del 30 de septiembre al 4 de octubre de 1967.

6 Cf. F. D’Ostillo, La storia del nouvo codice di Diritto canonico, Ciudad del Vaticano 1983, p. 37. Sobre este tema, vid. J. L. López Zubillaga, La doble decisión conforme en el proceso canónico Salamanca 2002, p. 303-317.

Sobre estos primeros pasos de esta Comisión vid. C. V. Gómez-Iglesias, La Pontificia Commissio Codici Iuris canonici recognoscendo en los años del Concilio Ecuménico Vaticano II: el plan de revisión de las leyes de la Iglesia, "IC" XLII (2002), p. 109-133. 
En el debate previo a la aprobación por el Sínodo de este texto, respondiendo a las objeciones presentadas por los Padres Sinodales, Mons. Felici, relator de este documento, se expresó en estos términos con relación a las causas matrimoniales: "Ius processuale, praesertim in causis matrimonialibus, attendat exigentiis humanitatis tum causarum brevitati consulendo, tum in maiore aequitate servanda. Conceptus rigidiores v.g. quoad notionem consummationis matrimonii ad maiorem aequitatem reducantur. Instantiae autem apud auctoritates regionales frequentiores sint, eis concedendo iudicium circa causas speciales v.g. pro applicatione privilegii fidei" 8 .

Mientras tanto, la labor de los grupos de trabajo del Colegio de Consultores no se había interrumpido. La subcomisión encargada de la reforma del Derecho Procesal tuvo como relator a Mons. Sabattani ${ }^{9}$. En 1970, apareció publicado el primer texto de este grupo de estudio ${ }^{10}$. En él ya se ofrece una solución para el problema de la apelación obligatoria de la sentencia declarativa de nulidad. Concretamente el párrafo 32 se refiere a la necesidad de reducir los trámites en la segunda instancia; pero sin eliminar por completo la obligatoriedad de la confirmación ${ }^{11}$.

La solución adoptada es la que se trasladó al M. P. Causas matrimoniales, donde se introduce la confirmación de sentencia mediante decreto, pero que

8 Cf. “Communicationes" 2 (1969), p. 97.

9 La composición de aquellos grupos de trabajo puede consultarse en "Communicationes" 1 (1969), p. 29-34. Se reunieron durante 1966 para establecer el marco de cuestiones generales, y organizar el calendario de trabajo, de modo que, pudiera completarse el primer documento al concluir el año 1970.

10 Cf. "Communicationes" 2 (1970), p. 181-182.

11 32. "Alterius instantiae alique contractio. a) Aliquando nullitas ita est solidis probationibus innixa, ut appellatio pro vinculo dici possit per se inutilis. Ast, in re tanti momenti, cautiones et praesidia aboleri nequeunt. Media via utilis visa est, qua recognitio superior non aufertur, sed reducitur quoad sollenitates. b) Huius attenuatae instantiae praecipua stadia et elementa haec sunt: aa) Defensor vinculi tribunalis appellationis exhibet suas animadversiones ut dicat utrum contra sententiam latam aliquid apponendum habeat, necne. bb) Perpensis talibus animadversionibus et visa sententia, Collegium suo decreto vel decisionem primi gradus ratam habet, vel ad ordunarium examen secundi gradus causam admittit. In priore casu, nemine recurrente, ius est coniugibus, post decem dies a notificatione decreti, novas nptias contrahendi. cc) Adeversus decretum ratiohabitionis Defensor vinculi vel pars, quae se gravatam putet, ius habent recurrendi ad superior Tribunal, sed tantummodo prolatis novis et gravibus argumentis, quae etiam praesto sint. dd) Defensor vinculi tertii gradus potest a recursu recedere: quo in casu Tribunal declarat litem finitam". Cf. "Communicationes" 2 (1970) 183-191. También en: Gordon-Grocholewsky, Documenta recentiora circa rem matrimonialem et processualem, Roma 1977, p. 234. 


\section{The Person and the Challenges \\ 186 Volume 5 (2015) Number 2, p. 181-223}

no suspende la apelación obligatoria del defensor del vínculo ante la sentencia que declara por vez primera la nulidad matrimonial.

Aunque la promulgación del M. P. Causas matrimoniales fue un hito importante en el proceso de revisión del Código, la aplicación práctica de esta norma, puso de manifiesto no pocas incoherencias en lo que respecta a la apelación en estas causas. El grupo de trabajo, tomando como base la abundante doctrina crítica y la jurisprudencia, reconsideraría la solución adoptada con respecto a la apelación abreviada.

De este modo, cuando concluye la primera fase con la propuesta del Schema canonum de modo procedendi pro tutela iurium seu processibus, de fecha 3 de noviembre de 1976, la Subcomisión había adoptado nuevas soluciones para los problemas que se presentaban las causas matrimoniales. Por lo que se refiere a la apelación, ya en el preámbulo del Schema se anuncia una novedad importante: por primera vez se menciona la posibilidad de la transmisión de oficio de las actas del proceso al tribunal superior ${ }^{12}$.

La redacción del que sería c. 347 del Schema, es la siguiente:

"1. El defensor del vínculo debe, dentro del plazo legítimo apelar la sentencia que declara por primera vez nulo el matrimonio; si comete negligencia en esto, las actas serán transmitidas de oficio, por la autoridad del presidente, al tribunal de apelación según las normas del c. 290, y en el futuro procédase como si la apelación hubiese sido propuesta por el defensor del vínculo.

2. El defensor del vínculo del tribunal superior, no puede renunciar a la apelación contra la primera sentencia que ha declarado la nulidad del matrimonio; pero cuanto antes, sopesadas con cuidado las actas, debe por escrito declarar si tiene algo que oponer o no contra la sentencia impugnada.

3. Examinadas las alegaciones del defensor del vínculo, referidas en el p. 2 y, si existen, las de las partes apelantes, el colegio mediante decreto confirmará la decisión o admitirá la causa a un nuevo examen ordinario.

12 Esquema de 1976: "Prenotanda, n. 57. Necessitas duplicis decisionis pro nullitate urgetur in Schemate, et statuitur quod, etiamsi defensor Vinculi primi gradus appellationem negligat, acta identidem transmittantur ad tribunal appellationis, quod ad ulteriora procedat "tamquam si appellatio a Vinculi defensore proposita sit”. Defensor vinculi apud tribunal appellationis non potest apellationi renuntiare. (c. 347, 1 et 2).

N. 58 Circa decretum ratihabitionis et ordinarium examen secundi gradus confirmatur praesens disciplina inducta a M.P. “Causas matrimoniales", VIII. Attamen, ex praecedenti can. 308, petita novae causa propositio contra duplicem decisionem pro nullitate exsecutionem sententiae non suspendit, nec in casu decreti ratihabitionis: contra id quod nunc evenit ex art. IX M.P. citati. Tribunal appellationis potest tamen, in singulis casibus, huiusmodi suspensionem iubere" ("Communicationes" 8 [1976] 195). 
4. Las prescripciones del c. 308 han de observarse aunque la sentencia que declaraba la nulidad del matrimonio hubiera sido confirmada, no con otra sentencia, sino mediante decreto"13.

Este es el texto que se distribuye para su consulta entre las diferentes Conferencias episcopales, los dicasterios de la Curia Romana y las Universidades Pontificias, entre otros. Quienes fueron consultados pudieron hacer llegar sus observaciones sobre él a la Comisión codificadora ${ }^{14}$.

b) Revisión del Esquema (1977-1980)

El texto del Schema de 1976 y las observaciones subsiguientes, fueron la base sobre la que trabajó la Comisión encargada de la revisión del Derecho Procesal, en la reunión que tuvo lugar el 30 de marzo de $1979^{15}$.

El debate comenzó ese día abordando la cuestión de la obligación del defensor del vínculo de apelar. Un tema cuyo tratamiento había sido propuesto a la Comisión por varios de los organismos de consulta a los que les había sido remitido el Esquema. En concreto a solicitud de uno de los Consultores se propuso examinar dos cuestiones distintas dentro de este punto:

1. Por un lado, si las sentencias que declaran por primera vez la nulidad del matrimonio han de ser sometidas, necesariamente, a nuevo examen.

2. De otro, si la carga de la apelación ha de ser asignada al defensor del vínculo.

Este mismo consultor se manifestó con respecto a la primera cuestión de forma positiva, mientras que sobre el segundo de los temas, pensaba que la apelación bien podría iniciarse siempre de oficio por el tribunal, de modo que fuera éste el que enviara el proceso a otra instancia. Este modo de proceder resultaba legítimo ya que la defensa del matrimonio sería asumida por el defensor del vínculo del tribunal de segunda instancia.

Casi todos los consultores estuvieron de acuerdo en que la sentencia de nulidad debía ser sometida a un nuevo examen, para que de este modo, y en la medida de lo posible, se evitaran posibles errores. Tanto más cuanto que en el c. 24 del Esquema se recogía la posibilidad de, en caso de necesidad, encomendar la causa a un juez único.

13 “Communicationes” 11 (1979) 265.

14 Vid. F. D’Ostilio, La storia..., p. 38. La fase de Consulta - según indica este autor - se prolongaría desde 1976 hasta noviembre de 1977.

15 Cf. “Communicationes” 11 (1979), p. 265-267. 
La única razón argüida para mantener la necesidad de la doble sentencia era la de evitar posibles errores en la misma; si bien es cierto que la posibilidad de que fuese en ocasiones un juez único el que dictase sentencia añadía la cuestión un matiz importante, podría parecer necesaria la confirmación de la sentencia emitida por un juez únicamente.

Lo cierto es que se acordó el exigir siempre un nuevo examen de la causa, y tras esta decisión el debate se centró en encontrar la fórmula más adecuada para realizarlo. Un nuevo examen irremediablemente alargaba la duración en el tiempo del proceso. Es lógico, pues, que todas las propuestas fuesen encaminadas a abreviar, en lo posible, la fase de confirmación.

Una de ellas fue admitir la posibilidad de dispensar en ocasiones de tener que acudir la segunda instancia. La Comisión no se mostró partidaria de esta solución, arguyendo que la concesión de tal dispensa, para que fuese otorgada, responsable y prudentemente, exigiría un periodo de tiempo considerable para examinar el proceso seguido hasta entonces, pues sólo entonces habría razón para esa dispensa. La otra opción que se planteó en aquel momento fue la de abreviar la fase de confirmación de sentencia, haciendo que se resolviera mediante decreto, tal como se había establecido en el M. P. Causas matrimoniales, una solución que, aunque presentaba algunos inconvenientes conocidos por los Consultores, fue la escogida para continuar el debate.

Por otra parte los miembros de la Comisión acogieron satisfechos la propuesta de que la apelación debiera iniciarse de oficio, esto es, a instancia del mismo tribunal. Al mismo tiempo, estuvieron de acuerdo también en la necesidad de dejar a salvo el derecho de apelar, tanto al defensor del vínculo como a las partes.

En este momento del debate, un Consultor insistió en plantear la posibilidad de suprimir la confirmación de la sentencia que declara por primera vez la nulidad del matrimonio, principalmente por los tres motivos siguientes:

a) Desde un punto de vista jurídico, estimaba que la necesidad de la apelación no responde a la mentalidad ni a la costumbre de algunos pueblos; para el Derecho de los Estados Unidos de Norteamérica, por ejemplo, resulta extraño la existencia de una apelación obligatoria.

b) Desde el punto de vista pastoral, señalaba que urgía establecer un procedimiento que acelerase la obtención de la sentencia de nulidad, ya que es deber de la Iglesia ofrecer soluciones a cuestiones que perturban la conciencia de sus fieles.

c) Desde el punto de vista práctico, también resultaba oportuna la desaparición de la apelación obligatoria. La grave situación de los tribunales (escasos, poco 
dotados y con una gran cantidad de causas), empeoraría con la imposición de la doble instancia.

A continuación, el Consultor que intervino para contestar al anterior, explicó que, en ocasiones, las costumbres de los pueblos y su cultura pueden resultar contrarias a las exigencias de la vida cristiana. Por consiguiente, no conviene cambiar instituciones simplemente por considerarlas contrarias a la "mentalidad de nuestra época". Por ejemplo, la doctrina de la Iglesia sobre la indisolubilidad del vínculo matrimonial, no puede variar según las épocas.

Contestando al argumento pastoral, recordó que estos motivos ya se tuvieron presentes en la redacción del M. P. Causas matrimoniales, y fueron los que llevaron a la instauración del proceso abreviado de confirmación, así como también a las normas especiales adoptadas para determinadas regiones.

Por lo que respecta a las razones alegadas de tipo práctico, respondió que la creación de los tribunales regionales, previstos en el nuevo Código, facilitará mucho la tramitación de los procesos matrimoniales, al menos en la segunda instancia.

Tras estas intervenciones, se procedió a la votación sobre la necesidad del examen en segundo grado, en la que ocho consultores se inclinaron por mantenerla, mientras sólo se registró un voto en contra.

La propuesta de aquel consultor, del que puede deducirse fácilmente que era norteamericano, no estaba exenta de razón. A cualquier jurista, no sólo a los de Estados Unidos, le extraña la existencia de una apelación en cualquier caso de una sentencia. Es frecuente que quienes llegan por vez primera a conocer sobre el desarrollo de las causas de nulidad, habitualmente por estar pensando en plantear la de su propio matrimonio, queden perplejos cuando se les informa que en cualquier caso van a acudir a una segunda instancia, o sea aunque ninguna de las partes hayan apelado. Es fácil deducir que la necesidad de un segundo proceso de confirmación en cualquier caso retrase la declaración de nulidad, sobre todo teniendo en cuenta el problema que ya se presentaba entonces, el de la falta de tribunales eclesiásticos bien dotados, un problema que, a pesar del optimismo del Consultor que le replicó, no tenía fácil solución como de hecho con el paso de los años se ha comprobado.

Sin embargo zanjada por el momento esta cuestión, la Comisión retomó el análisis del procedimiento de confirmación, que instauró el M. P. Causas matrimoniales. En concreto, se trataba de decidir, si sólo las sentencias pro nullitate, dadas en primer grado, podrían ser ratificadas por decreto, o si se extendería esta posibilidad a todas las sentencias declarativas de nulidad. 
Entonces dos Consultores se inclinaron por esta última solución, mientras que los restantes recomendaron tratar con prudencia las sentencias que declaran la nulidad, pero que han sido precedidas de una que la rechaza. Para estos casos, parecía lógico realizar un examen más detenido, tramitando esa ratificación mediante el proceso ordinario. Estos siete Consultores apoyaban su opinión en la respuesta que la Pontificia Comisión para la Interpretación de los Decretos del Concilio, emitió el 31 de octubre de 1973, y que se manifestaba en este sentido ${ }^{16}$.

Tras estas discusiones el can. 347 quedó del siguiente tenor:

1. La sentencia que declara por vez primera la nulidad de un matrimonio, junto con las apelaciones, si las hay, y demás actas del proceso, debe trasmitirse de oficio al tribunal de apelación dentro del plazo de veinte días a partir de la publicación de la sentencia.

2. Si la sentencia a favor de la nulidad se ha dictado en primera instancia, el tribunal de apelación, vistas las observaciones del defensor del vínculo y, si las hay, también de las partes, debe, mediante decreto, o confirmar la decisión sin demora o admitir la causa para que sea examinada con trámite ordinario en la nueva instancia ${ }^{17}$.

Esta formulación sustituía a los párrafos primero, segundo y tercero del canon 347 del Esquema; por su parte el cuarto pasaba a ser el segundo del canon 348. Con esta redacción se incorporó el Esquema parcial sobre los procesos al primer Esquema global o Proyecto de nuevo Código que el 29 de junio de 1980 fue presentado a Juan Pablo II y donde aparecía como canon 1634.

B) Fase de deliberación (Relatio, año 1981)

Una vez concluida la fase de revisión, comenzó la de deliberación, que tuvo como base el Proyecto de 1980.

Aunque antes hay que destacar que esta cuestión, la de la apelación obligatoria, fue objeto de debate en el Sínodo de los obispos que se celebró en octubre de 1980. Hubo durante la reunión dos intervenciones, la segunda que no estaba prevista en la agenda, se hizo a petición de algunos obispos que quisieron conocer el estado de la cuestión en el proyecto de nuevo Código ${ }^{18}$. En aquellos momentos el que en la opinión pública se hablara de paralelismo entre las declaraciones de nulidad y los procesos civiles de divorcio era

\footnotetext{
16 Cf. “AAS” 65 (1973), p. 620.

17 "Communicationes" 11 (1979) 267.

18 Vid. B. Ugge, La fase preliminare..., p. 77.
} 
un tema preocupante para parte de los obispos, pero, al mismo tiempo, la necesidad de diseñar un procedimiento declarativo de nulidad ágil que en un tiempo razonable diera lugar a la correspondiente sentencia era una cuestión que preocupaba también a muchos de los asistentes al Sínodo. Seguramente la confluencia de estas dos preocupaciones, que a mi modo de ver no son contrapuestas, propiciaría una cierta división en la forma de ver las soluciones que en la reforma se planteaban a una y a otra ${ }^{19}$.

\section{a) Primera discusión}

El texto del Proyecto fue remitido finalmente a setenta y cinco cardenales y obispos en julio de 1980. Como consecuencia de esta consulta, se recibieron en la Comisión una serie de documentos (animadversiones). Por lo que al c. 1634 se refiere, tenían en común la curiosa circunstancia de provenir de personas que desarrollan su labor pastoral en el ámbito cultural anglosajón.

i. Considerar la apelación "en conciencia del defensor del vínculo"

Los Cardenales Hume, O'Fiaich y Freeman, hicieron llegar a la Comisión de Reforma, sus observaciones acerca del texto del c. 1634 del Esquema de 1980, en tres documentos que en su mayor parte reproducían las propuestas, que en 1977, habían realizado la Conferencia Episcopal de Gran Bretaña y Gales y la de Irlanda, con respecto a la apelación en las causas matrimoniales.

En ellas se señalaba la posibilidad de dejar "en conciencia" al defensor del vínculo, la interposición o no de la apelación de la sentencia pro nullitate, cuando ésta ha sido otorgada por un tribunal colegiado. Aunque para aquellos casos en los que la sentencia hubiera sido dictada por un juez único, cabría contemplar un régimen diferente.

En Cardenal O'Fiaich, Arzobispo de Armagh, se limitaba a reproducir en su escrito la propuesta que la Conferencia Episcopal irlandesa realizó en $1977^{20}$.

19 La transcripción de lo tratado en aquella sesión aparece recogido en "Communicationes" 12 (1980), p. 215-233.

20 Observation of Cardinal O'Fiachi, Archbishop of Armagh on the Schema Codici Iuris Canonici 1980. "I repeat, whith emphasis, the proposal put forward in 1977 by the Irish Episcopal Conference to the effect: a) in general terms, thet the rule requiring an appeal in every first instance case in which a marriage is declared null and void, should be modified to allow for the differing circumstances of individual cases; and b) in particular, that i) the appeal be 'pro conscientia defensoris vinculi' if the case will have been decided three Judges; ii) the appeal be mandatory on the defender of the Bond if the case will have been decided by one Judge; but that the Defender of the Bond of secondinstance may renounce this appeal within a specified period of time". (Congregatio Plenaria Diebus 
El documento remitido por el Cardenal Hume, Arzobispo de Westminster, comenzaba, como el del anterior, recordando lo postulado en 1977 por la Conferencia Episcopal de Inglaterra y Gales ${ }^{21}$. HUME, no proponía la total supresión de la apelación de las sentencias declarativas de la nulidad, pues los abusos surgidos aquí y allá, demostraban claramente la necesidad de algunos controles procesales, pero entendía que estos debían ser flexibles.

El Arzobispo de Westminster consideraba que la apelación debía dejarse a la conciencia del defensor del vínculo, si dictó la sentencia en primer grado un tribunal de tres jueces; si, por el contrario, el tribunal de primera instancia constaba de un único juez, la apelación debería ser obligatoria. En cualquier caso, el defensor del vínculo de segunda instancia, tendría la facultad de desistir de la apelación.

Finalmente y a la vista de estas opiniones, El Cardenal HUME, proponía una redacción alternativa al c. 1634 y la adición de dos nuevos preceptos:

"Can. 1634.1. Dentro de los veinte días desde la publicación de la sentencia, otorgada por un juez único, que haya declarado por primera vez la nulidad del matrimonio, el defensor del vínculo debe recurrir al tribunal superior.

2. Pero si por cualquier razón dejara de hacerlo, las actas se trasmitirán de oficio, por la autoridad del juez, al tribunal de apelación y se procederá en adelante como si la apelación hubiese sido interpuesta por el defensor del vínculo.

3. Sin embargo, el defensor del vínculo del tribunal de apelación, oído el Vicario judicial o el juez por él mismo designado, examinado todo lo referente tanto al procedimiento cuanto al mérito de la causa, puede en conciencia renunciar en el plazo de un mes a la apelación de la que se habla en los párrafos 1 y 2".

“Can. 1634 bis. Dentro de los veinte días desde la publicación de la sentencia, otorgada por un colegio de jueces, la cual haya declarado la nulidad del matrimonio por primera vez, el defensor del vínculo tiene el derecho de recurrir en conciencia al tribunal superior".

"Can. 1634 ter. Si la sentencia a favor de la nulidad se ha dictado en primera instancia, el tribunal de apelación, examinadas las objeciones del defensor del

20-29 Octobris 1981 habita en "Acta et documenta Pontificiae Commissionis Codicis Iuris Canonici Recognoscendo" [Roma 1991], p. 105).

21 "That recommendation has not been incorporated into the Schema here under review. In deep, the report of the discussion of the matter at the Pontifical Commission carries no evidence that the proporsal of the Bishops of England and Wales was ever considered" (Submission by Cardinal Hume, Archbishop of Westminster on the Schema Codicis Iuris Canonici 1980 en Congregatio Plenaria..., p. 100). 
vínculo y, si las hubiere, de las partes, mediante un decreto suyo confirmará al punto la decisión o remitirá la causa a examen ordinario del nuevo grado"22.

En todo caso, el Cardenal Hume se muestra contrario a la solución de la "apelación de oficio" adoptada en el Proyecto de 1980. Considera que "obligar al tribunal a apelar contra su propia sentencia es jurídicamente absurdo y contrario a la sana razón"23.

Desde Sydney, el Cardenal Freeman propuso un párrafo que completase el texto del c. 1634 del Esquema: "Si la sentencia a favor de la nulidad del matrimonio fue dada en primer grado del juicio, el defensor del vínculo del tribunal de apelación tiene el derecho y el deber de determinar en conciencia si la apelación propuesta debe proseguirse o no"24.

ii. Posibilidad de dispensa de la revisión obligatoria

Canadá y los Estados Unidos tuvieron, como es sabido, unas normas especiales para la tramitación de las causas matrimoniales. Es lógico que defendieran el régimen especial, del que habían gozado hasta entonces.

Para el Cardenal canadiense Carter la redacción de este canon tal como estaba en el Proyecto, podía poner en peligro la aceptación del Código en algunas regiones ${ }^{25}$. Estimaba que eran muchos los obispos que pedían la supresión de la obligación de apelar y que no debía ser castigada toda la Iglesia por los abusos que habían surgido en algunos lugares ${ }^{26}$. Si, con todo, la Santa Sede consideraba que dicha obligación debía mantenerse, pedía que al menos se concediesen algunas excepciones, por lo que proponía que al final del párrafo 1 se añadiera: "a no ser que en casos excepcionales se proveyera de otro modo por la Santa Sede".

22 Cf. Submission by..., p. 101.

23 Cf. Submission by..., p. 100.

${ }^{24}$ En el texto de su animadversio, explica sus razones para sostener la proposición: "That there must be a control on the jurisprudence and quality of the work of first instance tribunals is fully accepted. On the otrher hand, marriages which are obviously invalid should not take up a disproportionate amount of the time of tribunals of appel. The requirement that a defender and three judges all study each single case, no matter how clear the nullity is, is disproportionate" (Congregatio Plenaria..., p. 101).

25 Vid. Animadversio Card. Carter, en Congregatio Plenaria..., p. 102.

26 "Bishops of the contries where marriage cases are studied have petitioned for the removal of this obligation. The reasons are evident and need not be repeated. Becouse of a few possible abuses that are considered to have ocurred here and there, the entire Church should not have to suffer" (Animadversio Card. Carter... en Congregatio Plenaria..., p. 102). 
Mucho más crítica era la postura de Mons. Bernardin, Presidente de la Comisión para Asuntos de Derecho Canónico de la Conferencia Nacional de Obispos Católicos de los Estados Unidos de América del Norte, lugar donde las normas especiales de procedimiento dictadas por Pablo VI llevaban en ese momento en vigor once años. Los obispos de los Estados Unidos se habían manifestado en diversas ocasiones sobre la oportunidad de que se dispensara en algunos casos de la obligación de confirmar todas las sentencias afirmativas. Esta posición la defendían partiendo de dos premisas concretas:

El derecho a apelar es irrenunciable. Las partes y el defensor del vínculo pueden apelar cualquier decisión.

Si las partes deciden no apelar y el defensor del vínculo cree que apelar a una segunda instancia es superfluo, la confirmación podría ser suspendida ${ }^{27}$.

Después de la experiencia de las normas norteamericanas (en abreviatura PEN), muchos obispos estaban firmemente persuadidos de que la apelación obligatoria no era esencial para la integridad del proceso matrimonial: la cooperación de las partes, del defensor del vínculo y la labor de los jueces en primera instancia ofrecen suficiente seguridad de que se obtendrá la certeza moral y se hará justicia. Para los casos en que se produjeran abusos, deberían existir otros medios para corregirlos diferentes de la apelación obligatoria.

En el supuesto de que la Santa Sede no quisiera introducir la posibilidad de dispensa de la apelación obligatoria en la ley universal de la Iglesia y dado que la situación afectaba especialmente a los Estados Unidos, la Conferencia Episcopal de este país solicitaba un régimen especial que permitiera dicha dispensa. Además a juicio del obispo norteamericano requerir un tribunal colegiado con intervención del defensor del vínculo para que otorguen un decreto de ratificación parecía excesivo; tales requisitos deberían exigirse sólo en los casos en que fuese interpuesta la apelación por el defensor del vínculo de primera instancia o por las partes $^{28}$.

27 " 1 . The right to appeal is steadfastly upheld. The parties and defender may appeal any decision.

2. If the parties choose not appeal, and the defender believes that the appeal to a second instance court wolud be superflous, the obligation could be waived" (Animadversio Archbishop Joseph Bernardin on the Schema CIC... en Congregatio Plenaria..., p. 103).

28 "Another difficulty is that canon 1634,2 requires a simple decree of confirmation to be iussued by a college of judges on the appellate level with the involvement of the appellate defender of the bond. To require so many tribunal officials to decide whether a sentence should be confirmed or not seems excessive. This is an especially important point since in metropolitan tribunals throughout the world, the professional personel available for tribunal activity are limited in number and are sorely needed to examinate petitions in First Instance. The appellate level personal should not be 
Junto a estas opiniones tendentes, si no a la desaparición, sí al menos a la restricción del examen obligatorio de las sentencias de nulidad, no faltó la animadversio del Card. Bafile que propone añadir al texto del c. 1634, 2: "si, por el contrario, la sentencia hubiese sido dictada en primer grado de juicio por un juez único según las normas del c. 1377, 4, el tribunal de apelación pasará siempre la causa a examen ordinario de nuevo grado", en vista de la gravedad de la materia ${ }^{29}$.

\section{iii. Decisión final}

Examinadas todas las alegaciones el parecer adoptado por el grupo de estudio "De los procesos" fue el siguiente:

"R. El grupo de consultores unánimemente piensa que las objeciones no deben ser admitidas. El sistema propuesto no es ni "jurídicamente absurdo" ni "contrario a la sana razón". Más que de apelación (el canon no habla de la apelación) se trata de la ulterior revisión en un asunto de la máxima importancia, como es el vínculo matrimonial.

Por otra parte, ya se ha provisto a las exigencias para la brevedad del procedimiento en segundo grado, a saber, con la posibilidad del decreto confirmatorio. Sin embargo, por causa de la gravedad de la materia, la cuestión a juzgar se difiere a los Padres de la Comisión en la próxima reunión plenaria"30.

\section{b) Reunión Plenaria de Octubre de 1981}

En Octubre de 1981, concretamente del 20 al 29 de ese mes, se celebraría la reunión plenaria de los Cardenales que tenía como misión emitir su juicio definitivo sobre el Proyecto del Código que se iba a presentar al Pontífice, concluyendo definitivamente la fase deliberativa.

Entre las seis cuestiones cuya decisión final quedó aplazada para la esta V y última Reunión Plenaria de la Pontificia Comisión para la Revisión del Código, aparecía la de la apelación en las causas matrimoniales (regulada

burdened with the review of automatic referals. They should be able to dedicate their expertise cases in which true appeals are made (either by the First Instance defender of the bond or by the parties)". Cf. Congregatio Plenaria..., p. 103.

29 "Propono ut in fine paragraphi addatur: "si vero sententia in primo iudicii gradu prolata fuertit a iudice unico ad normam can. 1377, 4, tribunal appellationis semper ad ordinarium examen novi gradus causam committat. Ratio: intuitu gravitatis materiae" (Animadversio Card. Bafile, en Congregatio Plenaria..., p. 106).

${ }^{30}$ Cf. "Communicationes" 16 (1984), p. 75. 
entonces en el c. 1634 del Esquema de 1980), tema éste sobre el cual, como acabamos de ver, no se había podido llegar a una decisión clara tras el primer debate ${ }^{31}$. Para el examen de esta cuestión, fueron sometidos de nuevo a análisis, los documentos aportados a la discusión y que ya fueron considerados en la denominada Relatio, y junto a estos, los votos elaborados por el entonces Secretario del Tribunal Supremo de la Signatura Apostólica, Mons. Sabattani y por el Padre Ignacio Gordon, prestigioso profesor de Derecho Procesal de la Universidad Gregoriana ${ }^{32}$.

Antes de que tuviese lugar la reunión, se habían fijado los términos en los que se iba a abordar la cuestión. Estos se concretaron en dos interrogantes:

A. Si en las causas de nulidad de matrimonio conviene exigir siempre la revisión de la sentencia que declara la nulidad por primera vez realizada en profundidad por el tribunal de apelación, tal como lo establece el 1634.

B. Si acaso es suficiente dejarlo a la conciencia del defensor del vínculo, o al menos exigirla sólo si la sentencia fue otorgada por un juez único ${ }^{33}$.

Precisamente en torno a estas cuestiones se articularon los votos elaborados por Sabattani y Gordon, muy distintos en la forma pero que por su profundidad considero muy interesantes de analizar.

i. Voto de Mons. Aurelio Sabattani. Los peligros de las "excesivas" sentencias de nulidad

El Voto que presentó el Secretario del Tribunal de la Signatura se orientaba de manera primordial a la crítica de las animadversiones presentadas en su momento por Mons. Bernardin en su calidad de Presidente de la Comisión para Asuntos Jurídicos de la Conferencia Episcopal del los EE.UU.

31 Vid. D’OSTILIO, F. La storia ..., p. 63-64.

32 Se trata de los siguientes documentos: Submission by Cardinal Hume, Animadversio Cardinal Freeman, Animadversio Cardinal Carter, el escrito presentado por el Arzobispo J. Bernardin, como Presidente de la Comisión para Asuntos Jurídicos de la Conferencia Episcopal de los Estados Unidos sobre el c. 1634 del Schema, Obsevation of Cardinal O'Fiaich, Animadversio Card. Freeman (incluida aquí aunque se trata de una precisión al c. 1373, 2) y la Animadversio Card. Bafile. Junto a estos se recogen los votos de los Consultores, en este caso los elaborados por Mons. Aurelio Sabattani y por el P. Ignacio Gordon. Todos estos textos aparecen reproducidos en el volumen Congregatio Plenaria..., p. 98-111.

33 "Porro a venerabilibus Patribus quaeritur:

A. Utrum in causis nullitatis matrimonii exigere semper oportet revisionem sententiae nullitatem primo declarantis a tribunali appellationis peragendam, ut satatuitur in can. 1634 ?

B. An potius sufficiat id relinquere conscientiae defensoris vinculi?; - aut saltem illam exigere tantum si sententia prolata sit a iudice unico" (Congregatio Plenaria..., p. 99). 
Comenzaba este Consultor su voto con una referencia a las alocuciones que el Santo Padre Juan Pablo II había dirigido a los miembros del Tribunal de la Rota Romana en los años 1980 y $1981^{34}$, concretamente a unos párrafos en los que el Pontífice ponía de manifiesto la influencia negativa que en la preparación para el matrimonio de los jóvenes suponía el hecho de que las sentencias de nulidad eclesiásticas fuesen obtenidas con excesiva facilidad. Juan Pablo II recordaba entonces también las palabras de Pío XII cuando explicaba que los jueces eclesiásticos no deben mostrarse propensos a declarar la nulidad del matrimonio sino más bien convalidar el matrimonio que se impugna. El Consultor concluía esta primera parte recordando que la exigencia de dos decisiones conformes no es sino un medio más para llegar a la convicción de la verdad, y la verdad es el fundamento de toda justicia.

No se puede ocultar - recordaba Sabattani - que las leyes no se otorgan 'en abstracto' sino que se dictan para una comunidad concreta, cuyas circunstancias deben ser analizadas por el legislador, pues sólo así las leyes lograrán su finalidad. Precisamente, teniendo en cuenta las condiciones especiales de la Iglesia en Norteamérica, se concedieron unas normas procesales particulares una de ellas otorgaban la posibilidad de que el ordinario local solicitase, de la Conferencia Episcopal, la potestad de dispensar de la apelación obligatoria. Para el autor del documento consecuencia directa al amparo de esta norma, casi el 96\% de las sentencias de nulidad dictadas por los tribunales eclesiásticos norteamericanos no fueron apeladas en segunda instancia.

La experiencia, tras once años de vigencia de esta normativa, resultaba desalentadora a juicio del Secretario de la Signatura que reproducía en su informe algunos datos acerca del elevadísimo número de nulidades concedidas a partir del año 1971, e incluso se hacía eco de la noticia de que en un tribunal eclesiástico norteamericano, concretamente en San Antonio (Texas), en el que se despacharon 626 declaraciones de nulidad en el año 1980, no había ningún juez con formación específica en Derecho Canónico ${ }^{35}$.

34 “AAS" 72 (1980), p. 173; “AAS" 73 (1981), p. 231-232.

35 Los datos que aporta provienen en su mayor parte de la información proporcionada por el International Herald Tribune, en su número de 28 de julio de 1981. En la diócesis de Dallas con cerca de 150.000 católicos se pronunciaron 465 sentencias de nulidad en $1979 .$. La exactitud de los datos que se recogen en este Voto es discutida en el documento con el que la Comisión para Asuntos Jurídicos de la Conferencia Episcopal norteamericana contesta este texto del Secretario de la Signatura, que será analizado más adelante. 
Concluía señalando que, efectivamente, cuestiones como la garantía del derecho a la defensa de las partes, o la seguridad en la proposición de las pruebas... son circunstancias que, en caso de haber sido quebrantadas, sólo podrían subsanarse si la causa se revisa en segunda instancia.

Tras el análisis de la experiencia norteamericana ${ }^{36}$, Mons. Sabattani respondió afirmativamente a la primera de las cuestiones que le habían sido sometidas, pronunciándose a favor de la necesidad de revisión de la causa y, en consecuencia, negativamente a la segunda, esto es, que no pudiera quedar de ningún modo a juicio del defensor del vínculo la oportunidad de esta revisión.

Añadió finalmente una previsión. Dado que la Conferencia Episcopal Norteamericana, había solicitado que se contemplase, aun tras la reforma de la legislación, un régimen especial que continuara permitiendo la dispensa de la revisión obligatoria de la causa, Sabattani alertaba sobre el peligro de confusión entre el orden judicial y el administrativo en caso de admitir este tipo de régimen excepcional, confiando la facultad de dispensar a una Comisión. Agregaba una observación de orden práctico: para otorgar tal dispensa, o habría de hacerse un examen detenido de las actas de la causa, que por razones de economía procesal, debería realizar el tribunal de apelación, o el examen se haría de modo meramente formal; en el primer caso estaríamos ante una auténtica confirmación de la sentencia y en el segundo ante un formalismo inútil y carente de sentido, que dejaría la decisión sin confirmar ${ }^{37}$.

ii. Contestación a las consideraciones de Mons. Sabattani

La Comisión para Asuntos Jurídicos de la Conferencia Episcopal de los EE.UU. presentó un texto donde analizaba, párrafo a párrafo, los "votos" elaborados por los mencionados consultores.

En primer lugar durante la reunión una intervención, en lengua latina, ante la Congregación Plenaria de la Comisión codificadora de Mons. Bernardin, en nombre de los miembros de la Conferencia Episcopal Norteamericana sintetizó la difícil y comprometida posición de la Iglesia estadounidense en lo que se refiere a los procesos matrimoniales ${ }^{38}$. No obstante, atendiendo además al

36 "Videtur quod maxime in hac re instet Conferentia Episcopalis Statuum Foederatorum Americae Septentrionalis, illius nempe nationis in qua magis patenter et frequenter verificantur facta supra exposita et defensores vinculi appellationem inutilem fere semper existimant" (Congregatio Plenaria..., p. 110).

37 Vid. Congregatio Plenaria..., p. 110.

38 Vid. Congregatio Plenaria..., p. 231-233. 
ruego que en aquel momento hizo el prelado a los miembros de la asamblea, he preferido no dejar de analizar el texto en lengua inglesa que fue sometido a la consideración de quienes formaban aquella Congregatio Plenaria ${ }^{39}$.

El informe presentado por el entonces Secretario de la Signatura Apostólica, Mons. Sabattani, comenzaba con la cita de un discurso del Papa Juan Pablo II a la Rota Romana en la que el Santo Padre recuerda palabras del Papa Pío XII. La cita destacaba que el hecho de que las declaraciones de nulidad fuesen superficiales, fáciles, apresuradas o faltas de sustancia debilitaba la doctrina de la Iglesia sobre la santidad y permanencia del vínculo matrimonial. La Conferencia Episcopal estadounidense en ese punto destacó que

"la admonición papal, sin embargo, no se refiere necesaria o intrínsecamente a la permanencia del sistema de revisión obligatoria de todas las sentencias afirmativas. La seriedad con que se otorgan las declaraciones de nulidad se encuentra sustancialmente en la regulación de todo el proceso de primera instancia, particularmente en el papel del defensor del vínculo, en el respeto estricto al ius defensionis, (...). Ciertamente, el proceso declarativo de nulidad no tiene por qué ser fácil o superficial por su propia naturaleza. Es razonable pensar en la complejidad de llegar jurídicamente a la certeza moral respecto a la nulidad de un matrimonio concreto. Resulta importante para la Iglesia establecer un proceso en el que las partes tengan que dedicar serios esfuerzos al plantearse determinados puntos sustanciales del consentimiento matrimonial (particularmente en cuanto a la capacidad y condiciones para el consentimiento marital válido), y no limitarse a tratar con legalismos puros como hace un tribunal en el fuero civil. Por consiguiente, respecto a la admonición del Santo Padre para evitar la frivolidad en las declaraciones de nulidad, sólo puede haber una respuesta: Accipitur"40.

Sin embargo fueron muchos los que aplaudieron la innovación que supuso, en el M.P. Causas matrimoniales, la introducción del proceso breve que concluía con el discutido decretum ratihabitionis. Estimaban que con ello se facilitaba

39 "Nostra Conferentiaa enixe rogat ut consideretur possibilitas in certis adiunctis dispensandi ab obligatione revidendi universas decissiones pro nulliate matrimonii in prima instantia pronuntiatas. $\mathrm{Si}$, autem hoc inopportunum esse iudicetur, rogamus saltem ut processus revisionis descriptus in can. 1634 simplicior fiat frotase secundum proposita quae reperiuntur in nostro supra memorato modo scripto" (Congregatio Plenaria..., p. 233).

40 Cf. Written animadversions, commisioned by the Canonical Affairs Committe of the U.S. Episcopal Conference, concerning the vota of his Excellency, the Archbishop Secretary of the Signatura Apostolica, and the Reverend Father Ignatius Gordon, S.I. Professor at the Pontifical Gregorian University, en Congregatio Plenaria..., p. 235-236. 
todo el procedimiento y se evitaban retrasos innecesarios. Ahora los prelados estadounidenses proponían otra fórmula para lograr el mismo fin:

"Las propuestas para alterar la naturaleza obligatoria de la revisión de apelación (por dispensa o por otras enmiendas del canon 1.634 del Proyecto) buscan introducir alguna flexibilidad adicional en la necesidad de confirmar la sentencia de nulidad sin disminuir esencialmente la seriedad del proceso. La revisión opcional supondría crear una vía diferente que aliviaría significativamente la carga de los tribunales de apelación. No se quiebra la seriedad del proceso, ni se trata de facilitar sin más la declaración de la nulidad del matrimonio en determinados casos"41.

En este orden de cosas, la Conferencia Episcopal norteamericana se mostraba orgullosa de la sencillez con la que se desarrollaban los procesos de nulidad matrimonial en su territorio ${ }^{42}$. Y valoraba positivamente la experiencia del procedimiento especial norteamericano frente a la opinión manifestada por Sabattani. El proceso, tal como se regulaba en las normas del PEN, se convertía en algo sencillo, y por consiguiente expeditivo y simple, siempre y cuando las partes no planteasen a tenor de lo previsto en la norma 23 nuevas investigaciones. Esto tuvo como efecto la disminución de la duración del proceso.

No pasa por alto la Conferencia Episcopal de EE.UU. el párrafo tercero del informe de Sabattani, donde se especificaba que el propósito de la revisión obligatoria era, ante todo, la prevención del error y del subjetivismo en la elaboración de la sentencia; la protección del matrimonio y de la familia sería un fin mediato, ya que derivaría de la ausencia de error en la estimación de su nulidad ${ }^{43}$.

De este planteamiento obtenía la Conferencia Episcopal Norteamericana una consecuencia:

"el verdadero efecto de la revisión obligatoria de la sentencia de nulidad, afecta muy poco a la visión del matrimonio presentada al pueblo de Dios en su totalidad. Su función es puramente interna, es una cuestión de organización jurisdiccional de la Iglesia. El deseo de mantener la revisión como obligatoria y no como opcional, se basa no en motivos prácticos sino en una cuestión de

${ }^{41}$ Written animadversions..., p. 236.

42 Written animadversions..., p. 236. Así lo destacaba, pero con diferente sentido el mismo Sabattani cuando reconocía que el procedimeinto para obtener la declaración de nulidad se había convertido en estos estados en el más simple en la Historia de la Iglesia, al menos en los siglos recientes.

43 Cf. Written animadversions..., p. 236. 
principios y sugiere la idea de que existe poca confianza en el rendimiento del personal de los tribunales de primera instancia, en particular de los jueces y del defensor del vínculo" ${ }^{\prime 4}$.

Por esta razón, la cuestión

"no es si la revisión obligatoria contribuye a la estabilidad del matrimonio y si su eliminación dañaría a esa estabilidad; sino si la revisión obligatoria evitaría errores y falsos juicios, de modo que su sustitución con algún tipo de revisión opcional propiciaría, por el contrario, un incremento de juicios erróneos y falsos" ${ }^{\prime 5}$. En definitiva, el debate sobre este tema no concernía tanto a la práctica del proceso como a la búsqueda de los principios de verdad y justicia que lo inspiran.

La Comisión norteamericana que elaboró estas animadversiones se mostró especialmente molesta con el punto del escrito de Sabattani en el que se trataba de demostrar, usando el ejemplo de los EE.UU., que la ausencia de una revisión obligatoria tuvo como consecuencia abusos por parte de jueces y defensores del vínculo, y propició declaraciones de nulidad falsas. El informe responde una por una a las situaciones denunciadas por el Secretario de la Signatura. Algunas versaban sobre la falta de análisis de las causas tramitadas en los EE.UU. y sobre la proliferación de sentencias declarativas de la nulidad ${ }^{46}$. Otras, se referían a la falta de preparación del personal encargado de los tribunales ${ }^{47}$.

44 Ibidem.

45 Cf. Written animadversions..., p. 236-237.

46 Algunas de sus estadísticas deberían ser completadas para situar las diócesis individuales en una perspectiva más precisa. Por ejemplo en Dallas. El arzobispo Sabattani expone que el tribunal, en el año 1.979, concedió 465 declaraciones de nulidad para una población católica de 150.000 personas. De hecho, en la diócesis de Dallas en el año 1.979 había 165.483 católicos entre una población total de 2.778.650 personas. Durante este año se celebraron 1.476 matrimonios, 782 de los cuales fueron matrimonios mixtos y 694 matrimonios de dos católicos. Al hablar de declaraciones de nulidad, es importante comprender la posición minoritaria en la que la mayoría de los católicos de los Estados Unidos se encuentran. Este factor es significativo ya que muchos matrimonios mixtos resultan de esta realidad demográfica y el tribunal diocesano local es requerido a resolver no meramente las peticiones de católicos sino también (a veces más frecuentemente) las peticiones de no católicos que desean casarse con católicos. Así de las 465 declaraciones de nulidad: en 153 casos ambas partes eran católicas; en 102 casos sólo una parte era católica; en 210 casos ambas partes eran no católicas. Siguen datos similares de los tribunales de Belleville, Little Rock. Written animadversions..., p. $238-239$.

47 "La primera ilustración de abusos que provienen de la naturaleza opcional de la revisión es la proliferación de sentencias afirmativas de tribunales en los que los jueces y defensores del vínculo tienen poca o ninguna educación jurídica oficial. Un ejemplo de tal situación es el tribunal de la Diócesis de San Antonio en Texas (EEUU) donde en el año 1.980, 626 matrimonios fueron declarados nulos. En el mismo año, 1.980 hubo 3.925 matrimonios de los cuales 971 fueron mixtos y 2.954 el matrimonio de dos católicos. Estas estadísticas, tomadas del Directorio Católico Oficial, 
Se criticaba también la rapidez con la que se celebraban algunos procesos, y la facilidad con la que se concedía la dispensa de la apelación, apuntando que muchos procesos se siguieron in fraudem legis. Por último censuró la escasa protección que en el PEN se ofrecía al ius defensionis de las partes. Pero ¿estas razones podían alegarse para fundamentar la revisión obligatoria de todas las sentencias de nulidad?

En lo que concierne a la seriedad y preparación de los tribunales eclesiásticos, la Conferencia Episcopal Norteamericana manifestó que

"la responsabilidad de mantener y fomentar jueces y defensores del vínculo instruidos, pertenece a todos los niveles de la autoridad eclesiástica: en primer lugar al obispo diocesano que debe ocuparse de su propio tribunal; en segundo lugar a la Conferencia Episcopal, que debería estudiar la calidad y el rendimiento de todos los tribunales en su región, y coordinar los recursos necesarios para conseguir que el personal de los tribunales mejore en competencia y pericia; y, en último término, a la Signatura Apostólica que actúa al nivel internacional para resolver situaciones en las que los miembros de los tribunales demuestran, en términos objetivos, que adolecen de importantes defectos en su pericia y rendimiento"48.

Pero, la existencia de jueces poco preparados no son razón para apoyar la revisión obligatoria de todos los casos de nulidad; serían razón para requerir una revisión directa de las causas dictadas por algún tribunal en particular, por aquellos tribunales de primera instancia, cuyo personal carezca de licenciados en Derecho canónico ${ }^{49}$.

Por lo que respeta al incremento de las causas de nulidad en los Estados Unidos, se interrogaba Mons. Sabattani sobre el motivo del notable aumento del número de sentencias de nulidad otorgadas en los Estados Unidos en un

son mencionadas a fin de situar el número de declaraciones de nulidad en perspectiva. Sin embargo parece que Mons. Sabbatani, al usar esta ilustración, da a entender que un número sustancial de estas 626 declaraciones son erróneas y falsas y que los matrimonios en cuestión no son de hecho nulos e inválidos. La conexión entre la falta de títulos académicos y las declaraciones de nulidad pretendidamente erróneas no tiene que ser directa. Ciertamente, todo tribunal de primera instancia debería estar provisto de canonistas formados debidamente y el canon propuesto 1.573, párrafo 3 intenta resolver este asunto directamente requiriendo que el personal posea al menos una licenciatura en Derecho Canónico. Pero vigente el Código de 1.917 con el uso de la frase vel ceteroqui periti en el canon 1.573, párrafo 4, parece que la pericia supliría la formación universitaria, difícil de obtenerse en diócesis como San Antonio en las que hay una grave escasez de clérigos para servir a los muchos católicos de la región". Cf. Written animadversions..., p. 238-239.

48 Cf. Written adnimadversions..., p. 236-237.

49 Cf. Written adnimadversions..., p. 238. 
periodo de diez años. El informe de la Conferencia Episcopal Norteamericana rechazaba la sospecha, insinuada por Sabattani, de que estas causas no estuvieran basadas en hechos verdaderos. Frente a esta presunción, se exponían en el informe una serie de razones que justificaban aquel importante aumento en el número de sentencias de nulidad. Algunos de los motivos citados, específicos de la situación de los Estados Unidos y otros referibles a la Iglesia universal.

Por ejemplo, había que tener en cuenta que en los años setenta

"ciertas decisiones de la Rota Romana instauraron la noción de incapacidad para asumir las cargas matrimoniales. El paso de estimar la psicosis como única enfermedad incapacitante, a considerar como tales a una serie de desórdenes de la personalidad, no psicóticos, aunque serios (tales como la personalidad psicopática y la personalidad histérica) fue un importante cambio puesto que la crisis de valores culturales en los Estados Unidos ha producido un desmesurado número de desórdenes de personalidad severos y serios entre la ciudadanía. Así como la neurosis parecía ser la dolencia predominante en tiempos de Freud, - se podía leer en el informe - en el mundo contemporáneo los desórdenes de personalidad y de comportamiento resultan extremadamente comunes y su efecto perjudica al matrimonio como consortium omnis vitae" ${ }^{\$ 50}$.

"En Estados Unidos, esta crisis de valores ha producido un índice de divorcios casi increíble. En 1.980 en Estados Unidos hubo un divorcio por cada dos matrimonios celebrados. Muchos católicos e incluso algunos no católicos $^{51}$, divorciados, acudían a los tribunales diocesanos para examinar la posible nulidad de su matrimonio, A estos había que añadir muchos católicos que habían vuelto a casarse fuera de la Iglesia, al ver rechazada su demanda de nulidad y que ante los cambios en la aplicación del concepto de incapacidad, intentaban de nuevo obtener la nulidad de su matrimonio canónico"s2.

En estos años se produjo además en los Estados Unidos una simplificación del proceso, operada gracias a las normas especiales dadas para los Estados Unidos y también por el M.P. Causas matrimoniales. Los tribunales de primera instancia, aplicando la jurisprudencia rotal, y usando de estas normas procesales, pudieron examinar y tomar decisiones sobre muchas demandas que llevaban años

50 Cf. Written adnimadversions..., p. 239.

51 Cf. Written adnimadversions..., p. 241. Por ejemplo en la Diócesis de Dallas, aproximadamente un tercio de las declaraciones de nulidad, implicaron a un demandante católico y a un demandado no católico.

52 Cf. Written adnimadversions..., p. 239. 
en espera de resolución ${ }^{53}$. Curiosamente y para resolver las muchas demandas recibidas, los tribunales optaron por seleccionar los casos más fáciles y más obvios para resolverlos en primer lugar." ${ }^{54}$ Sabedores de esto muchos abogados decidieron presentar las demandas sólo aquellos casos en los que la nulidad del matrimonio estaba bien probada y era clara.

Las estadísticas que indican la proporción del número de causas que concluyeron con una sentencia a favor de la nulidad en aquellos años, resultan - en estimación de la Conferencia Episcopal Norteamericana - algo engañosas, pues no reflejan los innumerables casos que, por aparecer a priori más complejos fueron retirados por los propios abogados.

Mons. Sabattani sugería también en su informe que el desproporcionado número de matrimonios observado en los EE.UU., demostraba que la mayor parte de estos se estaba celebrando sin una preparación pastoral adecuada ${ }^{55}$. En la contestación a aquel se podía leer:

"también los canonistas en Estados Unidos se habían percatado inmediatamente de la relación entre las muchas nulidades declaradas y la carencia de una preparación prematrimonial más rigurosa y efectiva. Ante esta situación en muchas diócesis se desarrollaron diferentes programas para potenciar la formación previa al matrimonio. Se puso especial interés en aconsejar a quienes pretendían contraer matrimonio siendo extremadamente jóvenes" ${ }^{\prime \prime 6}$.

Pero a continuación se apunta que fueron también motivos de índole pastoral los que llevaron a los miembros de la Conferencia Episcopal Norteamericana a reflexionar también sobre el interés pastoral por resolver la situación de los

53 "Es difícil imaginarse - explica el informe - los números referidos aquí. ¡Una estimación muy prudente es que en Estados Unidos había 7.000.000 de católicos divorciados; Hay que tener en cuenta además el hecho de que en, en países en los que los católicos forman una minoría, los tribunales de primera instancia son requeridos frecuentemente para examinar demandas, no sólo de católicos, sino también de muchos no católicos que pretenden contraer segundas nupcias con un católico. Al determinar el nivel de actividad de los tribunales instancia, es importante tener en cuenta tanto el número de católicos como también el de no católicos que residen en la zona”. Cf. Written adnimadversions..., p. 241.

54 Cf. Written adnimadversions..., p. 240.

55 Una opinión que en este punto incluye una grave afirmación cuando explica “... accuritus examen faciendum esset ante matrominii celebrationem, ne tot concubinatus in Ecclesia benedicantur...". Desde el Informe de la Conferencia Episcopal de EE.UU. se contesta puntualizando que en este caso el argumento de SABATTANI "parece impreciso ya que la preparación para el matrimonio puede proporcionar sólamente un mínimo de salvaguardia y un matrimonio inválido hecho de buena fe no debería ser considerado 'concubinato' sino un 'matrimonio putativo'". Cf. Written animadversions.., p. 240 .

56 Cf. Written adnimadversions..., p. 240. 
católicos que pretenden obtener la declaración de nulidad de su matrimonio y que se ven impedidos de llegar a ella por trabas procedimentales.

"Tampoco se puede pasar por alto - se lee en el informe de la Iglesia Estadounidense - el dolor de millones de católicos (por no mencionar los no católicos) que demandan la investigación de la nulidad alegada. Si el matrimonio de un católico es inválido, ¿no tiene ese católico el derecho (ius) a una investigación imparcial de su demanda de nulidad y a una sentencia favorable, en el caso de que la nulidad esté comprobada, más allá de toda duda razonable, en el fuero externo? Una declaración de nulidad, de acuerdo con la doctrina de la Iglesia y el procedimiento apropiado, no es un favor; es un derecho (ius) que se corresponde con el deber (officium) del tribunal competente de buscar y declarar la verdad. El cumplimiento de este obligación, sin embargo, resulta para los tribunales en algunos casos casi imposible" 57 . Esto debía constituir una preocupación para quienes desempeñan la función pastoral en la Iglesia, pues, como señalaba el informe, en el año 1975 el 95\% de todas las causas matrimoniales que se siguieron en primera instancia en el mundo, estaban localizadas en sólo once países, principalmente en Europa y Norteamérica. Estos once países representan sólo el $40 \%$ de la población católica mundial. Esto significa que en muchas partes del mundo (prácticamente para el $60 \%$ de los católicos) no hay un tribunal a disposición de los demandantes católicos"58.

Otro de los aspectos criticados por Sabattani se refería al hecho de que algunas declaraciones de nulidad habían sido otorgadas tras procesos que duraron sólo días, cuando no horas. La Comisión para los asuntos jurídicos de la Conferencia Episcopal de EE.UU. opinaba que este era un tema realmente preocupante, que debería de ser tratado individualmente, pero que tales abusos eran extremadamente raros, al contrario casi todos los procesos matrimoniales se prolongaban durante muchos meses excediéndose incluso de la limitación de tiempo prescrita por la ley canónica. Las declaraciones de nulidad apresuradas son excepciones a la regla y no deberían ser la base del argumento a favor de la revisión obligatoria que debe tratar de lo común, no de lo excepcional ${ }^{59}$.

En el mismo orden de denuncias Mons. Sabattani argüía que la Conferencia Episcopal de los Estados Unidos había abusado de la facultad de otorgar

\footnotetext{
57 Cf. Written adnimadversions..., p. 241.

58 Ibidem.

59 Written adnimadversions..., p. 242.
} 
la dispensa de la obligación apelar las sentencias declarativas de nulidad, convirtiendo, de este modo, la excepción en una regla.

Respondiendo a esta crítica, la Conferencia Episcopal estadounidense, recordaba el sentido que desde un primer momento tuvo esa dispensa, que se entendía, más que como una relajación de la ley para un caso particular, como una institución que debía contribuir a acelerar el trámite judicial de confirmación de sentencia, en aquellos casos en los que, en opinión del defensor del vínculo y del ordinario local, la causa no presentaba problemas para su ratificación ${ }^{60}$.

Sabattani calificaba el uso habitual de esta facultad de dispensar como abusivo. El informe en el que la Conferencia Episcopal le contestó, recordando que ni los defensores del vínculo que consentían tales dispensas, ni los ordinarios que, voluntariamente, las solicitaron tenían conciencia de estar abusando de una ley. Tampoco la Conferencia Episcopal consideraba su actitud un abuso,

"¿Por qué no? Todos estaban enterados de la situación que describían las estadísticas mencionadas. Todos sabían que los tribunales habían estado investigando y decidiendo solamente las nulidades matrimoniales más obvias. En consecuencia, las decisiones afirmativas resultaban habitualmente muy claras y la apelación obligatoria aparecía, en la mayor parte de los casos, realmente superflua" ${ }^{\prime 61}$.

Los Obispos norteamericanos consideraban lamentable el que hubieran llegado a dictarse tantas sentencias de nulidad; sin embargo, todas esas sentencias no hacían más que declarar, tras el proceso correspondiente, que se habían celebrado matrimonios inválidos. Cuando se llegaba, como sucedía en la mayor parte de las causas, a un alto grado de certeza sobre la nulidad declarada, los Obispos consideraban oportuno solicitar la dispensa y que la sentencia no fuese apelada. Basándose es esta experiencia, la Conferencia Episcopal Estadounidense, insistía en sugerir que la obligación de confirmar todas las sentencias declarativas de nulidad debía ser reformada. Al mismo tiempo, que manifestaba su protesta acerca del punto del votum preparado por Sabattani, que consideraba la actividad de los obispos norteamericanos en este asunto, durante los años de vigencia del PEN, un abuso de autoridad ${ }^{62}$.

El entonces Secretario de la Signatura también se hacía eco en su informe de que algunos habían tratado de obtener declaraciones de nulidad in fraudem

\footnotetext{
${ }^{60}$ Ibidem.

${ }^{61}$ Ibidem.

${ }^{62}$ Written adnimadversions..., p. 243.
} 
legis, al amparo de las normas concedidas para los EE.UU. La Conferencia Episcopal Norteamericana reconocía que había habido

"algunos abusos en este área y deberían ser cuidadosamente corregidos y prevenidos en el futuro. El canon propuesto para la determinación del forum partis actricis ayudaría a resolver este problema. Sin embargo, tales disputas y fraudes internacionales han sido relativamente mínimos, si se tiene en cuenta toda la experiencia de los Estados Unidos, y ninguna regla procedimental debería estar basada en esa excepción. En vez de requerir para cada caso una revisión mediante apelación, este tipo de abusos debería estar sometido a la estricta vigilancia del obispo diocesano, la Conferencia Episcopal y la Signatura Apostólica" $"$.

Se había referido Sabattani en su informe a la escasa protección que tenía en el PEN el ius defensionis. Para el Secretario de la Signatura sólo la segunda instancia podría salvaguardar el derecho a la defensa, cuando este le fuese denegado a la parte demandada, en primera instancia. En opinión de la Conferencia Episcopal Norteamericana su argumento olvidaba la posibilidad de plantear la querella de nulidad insanable de acuerdo con el párrafo 7 del canon 1.572 de Proyecto de Nuevo Código que decía: ius defensionis alterutri parti denegatum fuit ${ }^{64}$, y que ya estaba contemplado como motivo de nulidad específico en las normas del PEN. De cualquier modo, el informe de la Iglesia Norteamericana, coincidía con el votum de Sabattani en reconocer la extrema importancia que el respeto al ius defensionis presenta para la integridad del proceso matrimonial ${ }^{65}$.

Tras contestar detalladamente a cada una de las cuestiones a las que Mons. Sabattani se había referido en su votum, la Comisión para asuntos jurídicos de la Conferencia Episcopal Norteamericana reiteraba su propuesta de reformar el sistema de confirmación obligatoria de todas las sentencias que declaran la nulidad de un matrimonio.

La insistencia de la Conferencia Episcopal de los Estados Unidos en este punto se basaba en una experiencia considerable.

63 Ibidem.

64 Hay que recordar como las normas procedimentales otorgadas para EE.UU. y otros países ya preveían la ausencia del ius defensionis como causa autónoma y tipificada de nulidad insanable de la sentencia.

65 Written adnimadversions..., p. 243. 
"Una experiencia que demuestra que limitar la confirmación a aquellos casos que verdaderamente lo requieren, tiene la ventaja de liberar de trabajo a los jueces de los tribunales de apelación quienes, de este modo, tendrían oportunidad de estudiar con más profundidad los casos que les llegaran, que serían los más conflictivos. La Conferencia está convencida de que esto no supondría un menosprecio de la indisolubilidad del matrimonio"66.

A juicio de la Conferencia Episcopal Norteamericana, no sería un problema unir una dispensa, acto administrativo, con una fase del proceso, donde se desarrolla la función judicial. La forma de entender la plenitud de la potestad de jurisdicción en el ordenamiento jurídico de la Iglesia permite vincular estas dos diferentes funciones.

El documento de la Conferencia Episcopal estadounidense destacaba

"la importancia de la figura del defensor del vínculo, también como garante del ius defensionis de las partes. Si se admitiese que la revisión fuera discrecional en todos o algunos casos, el defensor del vínculo estaría dotado con una mayor responsabilidad. Tras estudiar la sentencia y las actas del proceso, él debería decidir si la sentencia habría de ser ejecutada sin más requisitos, o bien transmitir la causa al tribunal de apelación. En el segundo caso, podría o bien solicitar un segundo juicio, lo que se denomina una estricta apellatio, o bien simplemente solicitar la confirmación en aquellos casos en los que, aun estimando innecesario un segundo juicio, considere que conviene que otro juez ratifique la sentencia antes de la ejecución" ${ }^{67}$.

Por otra parte

"el ejercicio del poder administrativo de control resulta fundamental para garantizar la preparación e integridad de los tribunales en general, no sólo para controlar la integridad de una decisión particular. El obispo diocesano y, en su ámbito, la Signatura Apostólica tienen el deber de vigilar los tribunales de primera instancia, y especialmente la competencia e integridad del defensor del vínculo. No se trata de un control inmediato (realizado a cada causa individual), sino que sería un control mediato (realizado al personal y al funcionamiento de

66 Written adnimadversions..., p. 243-244.

67 "El defensor del vínculo de este modo es quien conduce una verdadera revisión y confirma o rehúsa confirmar la sentencia. (En el sistema de dispensa de la apelación de los Estados Unidos el ordinario del lugar ejerce su potestad judicial revisando la causa y las animadversiones del defensor del vínculo antes de decidir si la dispensa de la apelación debería ser concedida o si la causa era remitida para su revisión)" Written adnimadversions..., p. 244. 
los tribunales) que proteja los valores que en el voto del Arzobispo Sabattani se identifican como objetivos de la revisión obligatoria" ${ }^{98}$.

iii. Voto del P. Ignacio Gordon. La protección del vínculo matrimonial

El documento que el 10 de agosto de 1981 presentó ante la Comisión codificadora el Padre Ignacio Gordon recogía de una forma sintética, pero con una sistemática impecable, lo que el problema de la revisión de sentencias significaba en aquellos años.

Como se había venido haciendo durante todo el debate, el profesor de la Gregoriana distinguía dos problemas: por un lado, si debían ser revisadas todas las sentencias que declararan por primera vez la nulidad de un matrimonio; y por otro, tras solucionar la primera cuestión, se planteaba qué mecanismo procesal sería el más adecuado para realizarla.

Antes de entrar en el tema de fondo, Gordon se ocupó de recordar que entre las medidas propuestas por el Sínodo de los Obispos celebrado en 1967 para lograr la celeridad del proceso de nulidad matrimonial no se encontraba ninguna que afectase a la institución de la apelación ${ }^{69}$. Sin embargo, en el proceso de reforma algunos autores se habían manifestado en el sentido de limitar la apelación obligatoria a determinados casos, o bien dejarla en conciencia de cada defensor del vínculo ${ }^{70}$. Recordaba también Gordon que en 1971 el M.P. Causas matrimoniales y las Normas particulares dadas en 1970 para las causas matrimoniales que se siguiesen en los Estados Unidos, como antecedentes que, a su juicio, habían de tenerse en cuenta al abordar esta cuestión ${ }^{71}$.

Ante la obligatoriedad de la apelación cuando ni las partes privadas ni el defensor del vínculo, que poseen el derecho a hacerla, ven la necesidad de llevarla a cabo, se manifestó Gordon recordando que es la obligación de proteger el vínculo matrimonial la que justifica una revisión de la sentencia que declare

68 Written adnimadversions..., p. 244-245.

69 "De illis ac de tribunalibus ecclesiasticis data opera egit Synodus Episcoporum anni 1967. Patres, praesertim in altera et tertia Congregatione desiderium manifestarunt, tum ut causae matrimoniales nullitatis celeriore cursu perficerentur, tum ut Conferentiae Episcopales pollerent facultate ad tribunalia regionalia erigenda. Etiam sermo factus est de procedura, sub aspectibus descentralizationis et unificationis. Sed nullum verbum, quatum scimus, de instituto appellationis est prolatum" (Congregatio Plenaria..., p. 112).

${ }^{70}$ Cita los textos que pueden consultarse en GORDON, I, De nimia processum matrimonialium duratione en "PRMC" 58 (1969), p. 724-727.

71 Vid. Tibau-Durán, ¿Abre la Iglesia un portillo al divorcio?, “Ecclesia”, n 1057, 14-8-1971. 


\section{The Person and the Challenges \\ 210 Volume 5 (2015) Number 2, p. 181-223}

su invalidez ${ }^{72}$. El nuevo examen habrá de hacerlo un tribunal y no dejarlo en manos del defensor del vínculo, en tanto que considerar la intervención de este último decisiva para proceder o no a la revisión, supondría convertirles en un "superjuez" - usando la expresión del propio Gordon- con capacidad para decidir si la sentencia debe ejecutarse o no ${ }^{73}$. En este apartado recordó también los motivos que en su momento llevaron a Benedicto XIV a crear la figura del defensor del vínculo, y a establecer la necesidad de que hubiese dos sentencias declarativas de la nulidad para que ésta pudiese ejecutarse, unas razones que, a juicio de Gordon, aun a fines del siglo XX seguían teniendo actualidad.

Los representantes de determinadas Conferencias Episcopales habían expresado su opinión en el sentido de restringir los casos de revisión obligatoria de las causas de nulidad ${ }^{74}$. Se había propuesto a la Comisión que sólo debían ser revisadas de oficio las sentencias dictadas por tribunales unipersonales. También se había considerado la posibilidad de que, con el visto bueno del vicario judicial y el informe favorable del defensor del vínculo de segunda instancia, se pudiese dispensar de la necesidad de confirmar la sentencia de nulidad. Gordon rechazó estas propuestas porque la responsabilidad de la apelación recaería al final de nuevo en otro órgano unipersonal, que sería el defensor del vínculo del tribunal de segunda instancia ${ }^{75}$.

\footnotetext{
72 "Consequenter si indissolubilitas matrimonii, vocata in ius, meretur aliquam cautionem seriam - sicut datur partibus per ius appellandi -, non sufficit quod in causis matrimonialibus habeatur defensor vinculi, sed insuper requiritur ut prima sententia lata in favorem nullitatis, obligatoriae revisioni sibiciatur, sive haec subiectio fiat per appellationem obligatoriam defensoris vinculi, sive quovis alio modo efficaci, prout infra dicetur" (Votum Rev. Mi. P. I. GORDON... en Congregatio Plenaria..., p. 117).

73 "Defensor vinculi, iuxta communiter contingentia, est quidem vir capax tum ad colligendas ex actis aliquas animadversiones in favorem vinculi, tum ad appellandum 'ex officio'; sed non est 'superiudex' aptus ut quavis causa, si casus ferat, possit 'secundum propriam scientiam et conscientiam' appellationem opponere sententiae a collegio iudicum latae", (Votum Rev. Mi. P. I. GORDON... en Congregatio Plenaria..., p. 117).

74 "Haec altera opinio sustinetur reprasentatibus Conferentiae Episcoporum ex Angla, Hibernia et Australia, quibus videtur accedere restrictior petitio Conferentiae Episcoporum ex USA" (Congregatio Plenaria..., p. 119).

75 "Deinde, obligatio appellandi imposita defensori vinculi, quando tribunal primae instantiae fuit unipersonale, nulla est, siquidem talis obligatio aufertur ab eius collega secundae instantiae, qui constituit cum eo unicum officium per ordinem ad appellationem. Valde enim notandum est quod obligatio appellandi et actualis interpositio appellationis coram iudice 'a quo' iuvant si trahunt secum necessario revisionem causae apud tribunal secundi gradus; si autem illa necessitas cadit, quia prosecutio appellationis relinquitur arbitrio personae sustinentis munus defensoris vinculi in secunda instantia, beneficium illius obligationis appellandi est prorsus illusorium" (Congregatio Plenaria..., p. 120).
} 
Decidida la necesidad de proceder siempre a la revisión de la sentencia por otro tribunal, se planteó cuál era la forma más adecuada de realizarla. Gordon partió del régimen establecido en el M.P. Causas matrimoniales - entonces vigente - para analizar las diferentes objeciones que desde la doctrina se le hicieron a aquel proceso. Quedaba claro a la vista del informe la preocupación del ponente por facilitar y optimizar el procedimiento de revisión de la sentencia que declara la nulidad, motivando el decreto de ratificación, trasmitiendo todas las actas al tribunal de segunda instancia y creando nuevos tribunales regionales que facilitaran en acceso a éstos ${ }^{76}$.

Repasaba después el informe los mecanismos que se habían venido estableciendo por el ordenamiento canónico para iniciar una revisión de la primera sentencia de nulidad. Gordon destacó que en un primer momento se había creado la figura del defensor del vínculo durante el pontificado de Benedicto XIV. Su misión era la de provocar la apelación de la sentencia de nulidad. Después el Código de 1917, que conservó este mecanismo, estableció además la norma para el caso de que el defensor del vínculo incumpliera su obligación de apelar en el plazo que determinaba la ley, y facultaba al juez en este caso a compelerle a ello. En estos términos se pronunciaba también el M.P. Causas matrimoniales en 1971.

En un primer momento en la reforma se había continuado contemplando la obligación de apelar del defensor del vínculo. Sobre esta obligación se estableció después una "cláusula de seguridad", que determinaba que en aquellos casos en los que el defensor del vínculo no cumpliese con su obligación, la sentencia y las actas se trasmitiesen de oficio al tribunal de apelación. Dicha innovación motivó - como hizo ver Gordon - una reflexión entre los consultores. Esta transmisión de oficio de la sentencia, introducida en un primer momento con carácter subsidiario, apareció a los ojos de algunos consultores como la solución más acertada para sustituir a la apelación obligatoria ${ }^{77}$.

76 Congregatio Plenaria..., p. 123.

77 Fue defendida sobre todo por aquellos que abogaban por la libertad para manifestarse en conciencia del defensor del vínculo. "Opportunum est, propter observantiam defensori vinculi debitam, removere ab illo obligationem appellandi contra primam setentiam nullitati faventem" (Congregatio Plenaria..., p. 127). En el último esquema se contemplaba la transmisión de oficio de la sentencia de nulidad al tribunal de apelación, una solución que al entender de este consultor resultó especialmente acertada. 
La Conferencia Episcopal Inglesa se pronunció formalmente contra esta solución ${ }^{78}$. Entendía que no resultaba lógico que el tribunal procediese a instar una apelación contra una sentencia que acababa de pronunciar. Gordon explicó entonces el sentido correcto en que se debía entender la función de esta remisión automática o de oficio de las actas del proceso. El autor de informe expuso que no había que confundir la apelación con la transmisión de las actas para su revisión, pues se trata de conceptos diferentes ${ }^{79}$ abogando por una interpretación que considerara esta apelación realizada de oficio, no tanto por el tribunal como por el mismo Legislador implícitamente, y ello en aras a la protección de la indisolubilidad del vínculo ${ }^{80}$.

iv. Contestación al informe de Gordon

La Comisión para asuntos jurídicos de la Conferencia Episcopal de EE.UU. valoró también el informe elaborado por el Padre Ignacio Gordon. Hay que señalar que en primer lugar alabó la estructura de su informe por ser muy ordenado y estar cuidadosamente construido, lo que facilitaba el examen de los diversos argumentos en pro y en contra.

En algunos casos las alegaciones de Gordon coinciden con las realizadas por Sabattani. Por ejemplo, vuelve a incidir en las estadísticas sobre las dispensas de la obligación de apelar otorgadas. Sobre todo, de las dadas después de la prórroga de las normas procedimentales especiales en 1974. La Conferencia Episcopal Norteamericana en este punto se remitió a lo contestado en el mismo documento al Secretario de la Signatura.

Gordon mencionaba también dos documentos de la Signatura Apostólica que relacionaban irregularidades que se detectaron, unas en la actuación de algunos tribunales eclesiásticos norteamericanos ${ }^{81}$ y a los que la Conferencia

78 Cf. Submission by Cardinal Hume... en Congregatio Plenaria..., p. 100.

79 "Haec animadversio non tenet, quia confundit appellationem cum transmissione actorum, qui sunt conceptus valde diversi “ (Congregatio Plenaria..., p. 126).

80 Refiriéndose a la obligación de trasmitir las actas del proceso escribe "Tamen haec obligatio non transfertur in iudices, sed satis est ut tribunal teneatur ex oficcio ad acta tribunali appellationis trasmitena, iussu expresso Legislatoris. De cetero bene aestimari potest hic iussum supponere appellationem ab eodem Legislatore implicite factam fuisse" (Congregatio Plenaria..., p. 127).

81 El primero de ellos, de 14 de diciembre de 1977 se refería a la actividad de cuatro tribunales Estadounidenses. La Comisión de obispos norteamericanos quería aclarar que aquel memorándum citaba abusos alegados respecto a casos específicos. Cuando las acusaciones fueron investigadas en los tribunales respectivos, a petición del presidente de la Conferencia Episcopal, se descubrió que aquellas se fundaban en informaciones imprecisas e incompletas. El resultado de estas cuidadosas 
Episcopal de EEUU dio respuesta en su momento y otras por el uso incorrecto del denominado fuero de la parte actora ${ }^{82}$.

En un inciso la Conferencia Episcopal Norteamericana se mostraba molesta porque el Profesor de la Gregoriana minusvaloraba las normas reguladoras del proceso experimental norteamericano que consideraban habían sido la aportación de su país a la reforma del proceso en el Derecho Canónico ${ }^{83}$.

Tras contestar a estas cuestiones generales, el informe presentado por la Conferencia Episcopal de los Estados Unidos respondió, párrafo a párrafo, la réplica de Gordon a las propuestas que desde ese organismo se habían hecho a la Comisión para la reforma del Derecho Canónico.

No compartía la Conferencia Episcopal Norteamericana la visión que Gordon ofrecía sobre la figura y la función del defensor del vínculo, y que le llevó a escribir que "el derecho que posee del defensor del vínculo a apelar es poco significativo ya que él no es un 'superjuez', (superiudex) si no una persona cuya capacidad está limitada a articular algunas animadversiones a favor del vínculo y a apelar ex officio. Así considerada, esta persona tampoco parecía capaz para asumir una apelación secundum propriam scientiam et conscientiam." En opinión de los Obispos norteamericanos, "esta perspectiva desvirtúa el papel del defensor del vínculo y degrada sus capacidades, olvidando los términos en los que el nuevo código describía las cualidades del defensor del vínculo (canon 1.373, párrafo 3). De modo que la afirmación de Gordon de que el defensor del vínculo no es persona apropiada para interponer una

investigaciones fue remitido a la Signatura Apostólica con la esperanza de que su preocupación disminuyera. A estas últimas averiguaciones no se refiere en ningún momento Gordon. Vid. Z. Grocholewski, Declaration of the Apostolic Signature on the competence of Ecclesiastical tribunals in the United States of America, "ME" 104 (1979), p. 139-161.

82 En efecto una carta de la Signatura Apostólica fue enviada en abril de 1978 a los obispos mejicanos con referencia a la utilización del fuero de la parte actora como fundamento de competencia judicial (norma 7, del PEN) cuando la parte demandada residía en una nación distinta a los Estados Unidos. Las precauciones establecidas en este documento para el uso de los fueros extraordinarios que determinan la competencia ya habían sido incorporadas al Código en cuyos esquemas se trabaja", Cf. Written adnimadversions..., p. 245.

83 Cf. Para los obispos estadounidenses las Normas Procedimentales Americanas no han sido una ley particular más, han constituido una parte importante en la historia del desarrollo de las leyes procedimentales de la Iglesia, representada en el nivel de ley universal por el Causas matrimoniales y culminando en el Schema de processibus de 1980 Written adnimadversions... cit. p. 246. En el texto del Voto del P. Gordon, se manifiesta su opinión acerca de la importancia limitada que tuvieron las normas del Pen y como sus preceptos no tuvieron acogida en el Causas matrimoniales. excepto la n. 12 que encuentra parangón en la norma IV, 3 del M.P. Cf. Congregatio Plenaria..., p. 115. 
apelación secundum propriam scientiam et conscientiam, es difícil de aceptar a la luz del ius appellationis de que disfruta como resultado del canon 1.580"

Para Gordon la posibilidad de que el defensor del vínculo revisase el proceso y decidiese si debía o no proponer la apelación, equivaldría a un segundo juicio de nulidad, que, como juicio que es, debería ser realizado por un tribunal. Pero para los miembros de la Comisión de asuntos jurídicos de la Conferencia Episcopal Norteamericana

"el defensor del vínculo al revisar las actas y la sentencia está, ciertamente haciendo un juicio, un juicio para el que él debería ser completamente capaz, y que trataría de decidir si la sentencia de primera instancia debe ser confirmada inmediatamente o trasmitida al tribunal de apelación para su posterior revisión en juicio" $"$.

En una actitud de cierta "desconfianza" respecto al defensor del vínculo, Gordon advertía cómo la posición de éste en el caso de que propusiera la apelación resultaría comprometida, dado que él mismo forma parte del tribunal que ha dictado la sentencia. Los restantes miembros del tribunal podrían enojarse e incluso solicitar su traslado, si transmite habitualmente las causas para su revisión. La Conferencia Episcopal Norteamericana defendía su propuesta entendiendo que

"con la redacción presentada disminuiría ese temor a suscitar la animosidad de los otros miembros del tribunal, ya que se permitiría al defensor del vínculo confirmar inmediatamente o remitir la causa a segunda instancia en algunos casos para su confirmación, en otros para un segundo juicio. El defensor del vínculo estaría, a veces, dispuesto a recomendar la confirmación inmediata de la sentencia, una decisión que no equivale a interponer una apelación en sentido estricto contra la sentencia afirmativa de los jueces de su tribunal. De vez en cuando, sin embargo, el defensor del vínculo se vería obligado a enviar la causa a segunda instancia para que se siga una apelación estricta, (buscando su revocación). Hará una cosa u otra, según lo aprecie, siempre teniendo en cuenta el cumplimiento de su misión esencial, el munus defendendi vinculum matrimoniale. Decir que ejercitar aquello que le corresponde según el derecho le puede causar al defensor del vínculo problemas de relación con

${ }^{84}$ Cf. Written adnimadversions..., p. 247.
${ }_{85}$ Ibidem. 
los demás miembros del tribunal, no es razón de peso para negar la validez de sus alegaciones y su honradez cuando se trate de ejercer su ius appellationis ${ }^{86}$.

Otro de los argumentos empleados por el Profesor de la Gregoriana para justificar la revisión obligatoria, se fundaba en la apreciación de que los jueces no son infalibles. Si bien es cierto que esto último es una realidad, esta objeción no parecía motivo suficiente que justificase la revisión obligatoria, al menos para la Conferencia Episcopal de los EE.UU. que recurría de nuevo a su argumento de que no se puede establecer la regla basándose en la excepción. En efecto, escribían los obispos norteamericanos

"todos los jueces pueden cometer errores, los jueces de apelación igual que los jueces de primera instancia. El proceso en la Iglesia no se puede basar en la presunción de que los jueces yerran en algunas o incluso en muchas ocasiones. La presunción de derecho es precisamente la contraria: aunque todos los jueces son falibles, el proceso judicial que siguen les permite salvaguardar la verdad y la justicia en nombre de la Iglesia. El error es la excepción, no la regla"87.

La conclusión a la que llegaba Gordon es que solamente la revisión obligatoria de sentencias de primera instancia en un nivel de apelación era capaz de proporcionar una seria salvaguardia (cautionem seriam) para la indisolubilidad del matrimonio ${ }^{88}$.

En otro orden de cosas, la Conferencia Episcopal Norteamericana no encontraba afortunado el paralelismo que Gordon pretendía establecer entre el periodo histórico en el que se creó la figura del defensor del vínculo y se estableció el requisito de las dos sentencias concordantes,(esto es la promulgación de la bula Dei miseratione, dada por Benedicto XIV el 3 de Noviembre de 1741), y el momento de la discusión. Este paralelismo iba a servirle a Gordon de argumento histórico que justificara de nuevo, en el momento de la reforma del Derecho de la Iglesia, la necesidad de revisión obligatoria: Itaque, ad idem

86 Ibidem.

87 Cf. Written adnimadversions..., p. 248.

88 Esto le llevaba a su vez a no considerar otras precauciones que podrían adoptarse en el proceso de primera instancia: la necesidad de la adecuada formación jurídico-canónica del defensor del vínculo de primera instancia; la determinación del papel de éste al examinar la sentencia judicial, ejerciendo, en el caso que fuese necesario, su ius appellationis; y por último el respeto a la apelación como un ejercicio del ius defensionis de la parte demandada que ejercitará con la ayuda de procurador y abogado conocedores del Derecho canónico. Cf. Written adnimadversions..., p. 248. 
malum vitandum, idem remedium adhibendum est ${ }^{89}$. Escribía el representante de los obispos norteamericanos

"Desde una perspectiva histórica este argumento es cuestionable, el Papa Benedicto XIV (Prospero Lambertini) fue uno de los más doctos, enérgicos y humanos canonistas, que fue además elegido para ser legislador supremo de la Iglesia. Sus reformas, en materia procesal, estuvieron dirigidas a solucionar los graves abusos que se producían en Polonia, y buscaron introducir una voz de razón y orden en el ambiente de escepticismo dieciochesco. La situación con la que Benedicto XIV se enfrentó en Polonia no es, sin embargo, comparable de ningún modo a la gran crisis mundial que se observa en la nuestra sociedad. No pueden equipararse. El ejemplo específico ofrecido por el padre Gordon (múltiples anulaciones seguidas de múltiples matrimonios) se verifica pocas veces en nuestro tiempo, ni siquiera en aquellos tribunales que han incrementado el número de declaraciones de nulidad (...). Si el genio de Benedicto XIV es comprendido adecuadamente en un sentido histórico válido, el adagio del padre Gordon citado antes debe ser invertido: Itaque, ad diversum malum evitandum, aliud remedium adhibendum est... Uno se pregunta si Benedicto XIV, insigne canonista y miembro de la curia, en el caso de que viviera hoy, no crearía de hecho un proceso completamente nuevo (...) para resolver la situación actual en el mundo a la luz de la indisolubilidad marital" $"$.

Gordon señalaba la revisión de las sentencias como el modo de garantizar la certeza de las declaraciones de nulidad preguntándose sobre la existencia de otros medios para lograrlo. En este punto, el informe elaborado por la Conferencia Episcopal Norteamericana traía a colación el modus del cardenal Freeman que se refería precisamente a este tema de las garantías en la función de la justicia. Aquél explicaba:

"es totalmente aceptado que debe haber un control sobre las sentencias y sobre la eficiencia del trabajo de los tribunales de primera instancia. Al mismo tiempo es fácil aceptar que los matrimonios claramente inválidos no deberían absorber una cantidad de tiempo desproporcionada de los tribunales de apelación. El requisito de que un defensor y tres jueces estudien cada caso individualmente, sin importar cuán clara sea la nulidad, resulta desproporcionado. La Signatura tiene como misión ejercer la vigilancia de los tribunales, pero en la práctica solamente puede hacer esto a través de los obispos. Encomendar al obispo

89 Ibidem.

90 Cf. Written adnimadversions..., p. 249. 
este control, resulta mucho más eficaz. Hay que tener en cuenta que éste sólo trataría con uno o, en cualquier caso, unos pocos defensores. Si se observaran abusos en algunos lugares o en un país, entonces la Iglesia deberá afrontar esos problemas directamente, y no permitir que esos abusos particulares dicten la ley general de la Iglesia. En la mayor parte del mundo los tribunales eclesiásticos son percibidos como cautelosos y prudentes en su trabajo"

Había por tanto, otros medios de realizar un control eficaz sobre las sentencias de nulidad. Estos medios eran, de un lado los indirectos (previsión en todos los casos de la confirmación de sentencias) y de otro, los directos (ejercicio del control sobre los tribunales eclesiásticos). Para los miembros de la Conferencia Episcopal Norteamericana, el tema central del desacuerdo con el informe de Gordon era el siguiente: la forma óptima de ejercer control sobre las decisiones de los tribunales ¿es la realizada sobre cada caso examinado por estos - como sostiene Gordon - o es preferible mantener una vigilancia sobre estos tribunales para evitar que comentan errores en sus decisiones? La Conferencia Episcopal de los EE.UU. estimaba que es prioritaria el control de los tribunales siendo éste

"un deber que compete principalmente y por derecho divino al obispo diocesano, y en la medida en la que la nación o región eclesiástica sea un elemento importante en derecho procesal, (por ejemplo con respecto a la competencia o los tribunales regionales), la Conferencia Episcopal también debería asumir la responsabilidad sobre la actividad de los tribunales en su región. En el nivel universal esa responsabilidad, normalmente, la asume la Signatura Apostólica"92.

Cabe recordar aquí- y así lo hacía este documento- cómo "la Signatura Apostólica había venido ejerciendo legítimamente la vigilancia de determinados tribunales diocesanos de primera instancia, revisando casos seleccionados y reprobando, cuando fuese necesario, la actividad del tribunal. Si la Comisión estuviera de acuerdo en suprimir la revisión obligatoria de las sentencias de nulidad, sería apropiado que las conferencias episcopales de cada país adoptaran el procedimiento similar al que ya posee la Signatura y conforme a éste realizaran una supervisión más inmediata y cercana sobre sus tribunales ${ }^{93}$.

91 Cf. Congregatio Plenaria..., p. 101-102.

92 Cf. Written adnimadversions..., p. 250.

93 De hecho la Conferencia Episcopal EEUU poseía ya un sistema para controlar los tribunales. Un equipo de expertos, que incluye obispos y canonistas, indagan en la actividad del tribunal y finalmente señalan las deficiencias observadas que de este modo podrán ser corregidas. Al mismo 
En conclusión, la Conferencia Episcopal Estadounidense estimaba que, mejor que obligar a la revisión de cada causa (como se señalaba en el propuesto canon 1.634) parecería más aconsejable y eficaz fijar la obligación de establecer un control sobre cada tribunal. Esta obligación afectaría a cada conferencia episcopal, que sería la responsable de la supervisión de todos los tribunales de su jurisdicción eclesiástica ${ }^{94}$.

Lógicamente todas estas decisiones sobre "otros medios" de corregir la actuaciones y prevenir los abusos en los tribunales, no podían ser contempladas en el Libro que el Código dedicaría a los procesos - explica la Conferencia Episcopal Estadounidense -, pues

"no se trata propiamente de medios procesales, más bien son medidas que especifican o concretan el deber sustantivo, (officium) de la autoridad eclesiástica de vigilar la administración de justicia. Estos medios deben ser adecuados para adaptarse a las diferentes situaciones que puedan surgir en distintos lugares del mundo. Habrán de ser, por tanto, objeto de regulación bien del derecho particular o de las normas que se refieran al ejercicio del poder administrativo. No obstante, - sugería el documento - un canon general podría añadirse como introducción al Titulus I-De Causis Matrimonialibus destacando la responsabilidad de la autoridad de la Iglesia, en sus diferentes niveles, respecto al mantenimiento de la integridad de los tribunales en sus respectivas jurisdicciones y la calidad de las sentencias que dictan" $" 95$.

En uno de sus últimos apartados, volvía de nuevo el debate sobre la figura del defensor del vínculo, ahora especialmente refiriéndose al de segunda instancia, y ello en tanto una de las propuestas incide sobre la posibilidad de que el de segunda instancia pueda decidir si debe ejecutarse la sentencia de primera o proseguirse el proceso en segunda. En este punto Gordon había escrito que

"el defensor del vínculo de segunda instancia forma un officium unicum con el defensor del vínculo de primera instancia y describe al primero como collega en la segunda instancia. Al hacerlo así, el padre Gordon parece subestimar la integridad del defensor del vínculo y su pericia que debería ser similar a la del juez. De hecho, aunque el papel del defensor del vínculo en ambos niveles puede ser considerado teóricamente un officium unicum, en la práctica, los dos

tiempo estos expertos pueden sugerir métodos para mejorar la eficacia de los procesos" Written adnimadversions..., p. 250.

94 Ibidem.

95 Cf. Written adnimadversions..., p. 251. 
defensores del vínculo son ciertamente colegas pero independientes entre ellos. Puesto que la función principal de éste es, como su título revela, 'defender el vínculo del matrimonio', nunca renunciará a una appellatio, a no ser que su consideración fuera completamente inútil y superflua" ${ }^{96}$.

En efecto no le parecía a Gordon que el defensor del vínculo del tribunal de segunda instancia fuese la persona idónea para adoptar la decisión de proseguir o no con la confirmación de la sentencia de nulidad. De modo que, cuando la Conferencia Episcopal Estadounidense responde al informe elaborado por el profesor de la Gregoriana, dice:

"parece como si el objetivo principal de aquellos que pretenden un cambio en el sistema de revisión en grado de apelación, sea el buscar el modo para que siempre intervengan tres jueces y un defensor del vínculo simplemente para confirmar una causa. ¿Por qué se necesitan tantas personas para revisar las actas de una causa ya investigada y decidida en primera instancia? El objetivo de la revisión, tal como se proponía, es simplemente decidir si la causa justifica un decreto de confirmación o una remisión a un juicio completo en segunda instancia. Una propuesta ha sugerido que esta disyuntiva sea resuelta por el defensor del vínculo del tribunal de apelación, que usaría de este modo del ius renuntiationis que se recoge en el canon 1.588 párrafo 2 . No obstante quizás, se podría llegar al compromiso de determinar que un sólo juez de segunda instancia fuera reconocido como el 'juez de revisión' (iudex revisionis) a quien se garantizaría el derecho de revisar todas las sentencias afirmativas de primera instancia, sin involucrar a otro personal del nivel de apelación a no ser que el caso lo requiriera" ${ }^{97}$.

\section{v. Discusión final}

Las precisiones realizadas por la Conferencia Episcopal de Estados Unidos a los informes de estos Consultores, fueron remitidos junto a los restantes documentos a la Comisión codificadora. Todos estos textos ayudaron a los miembros de la Comisión a decidir sobre las dos cuestiones en torno a las cuales se centró el debate oral y que fueron estas:

"A. Si en las causas de nulidad de matrimonio conviene exigir siempre la revisión de la sentencia que declara la nulidad por primera vez realizada en profundidad por el tribunal de apelación, tal como lo establece el 1634.

\footnotetext{
96 Ibidem.

97 Cf. Written adnimadversions..., p. 252.
} 
B. Si acaso es suficiente dejarlo a la conciencia del defensor del vínculo, o al menos exigirla sólo si la sentencia fue otorgada por un juez único"98.

El debate se celebró el 21 de octubre de 1981. Presidía el Cardenal Felici, que en primer lugar dio la palabra a Mons. Castillo Lara, que pronunció una palabras en las que ponía de manifiesto la importancia de la cuestión a debatir, sobre todo teniendo en cuenta la relación de este tema con una idea que se había ido formando en la opinión pública acerca del proceso de nulidad matrimonial que en muchos casos confundía a los propios cristianos ${ }^{99}$.

Intervinieron a continuación el Cardenal Rugambwa, que recordó cómo en 1977, se había aprobado el respeto al principio matrimonium gaudet favore iuris, y que por esta razón estimaba que resulta necesaria la revisión, en cualquier caso, de las sentencias cuando declaran la nulidad del matrimonio ${ }^{100}$.

Más tarde tanto el Cardenal Garrone como el Card. Palazzini, se manifestaron en el mismo sentido abogando por el mantenimiento de la revisión obligatoria de las sentencias de nulidad ${ }^{101}$. No usó su turno el Cardenal Bafile ${ }^{102}$. A continuación le correspondía la palabra al Cardenal Hume ${ }^{103}$; su intervención tenía especial interés pues él era el autor una de las propuestas de reforma. Hume tras defender sus argumentos solicitó, un cambio en el ordo procedendi, que permitiese una recapitulación, petición a la que se sumó el Cardenal Parecattil, y que sin embargo no fue aceptada por el Presidente que entendía que esto podría suponer una dilación extraordinaria del debate ${ }^{104}$, no obstante este Cardenal propuso la apelación obligatoria al tribunal de segunda instancia tal como ya se había incorporado incluso al Proyecto de Código oriental ${ }^{105}$.

\footnotetext{
98 Cf. Congregatio Plenaria..., p. 99.

99 Cf. Congregatio Plenaria..., p. 261-262.

${ }^{100}$ Cf. Congregatio Plenaria..., p. 262-263.

${ }^{101}$ Cf. Congregatio Plenaria..., p. 263-264.

102 Precisamente este prelado se había manifestado por escrito sugiriendo la oportunidad de señalar que siempre que la sentencia de nulidad fuese dada por un juez único, debería de procederse en apelacion ordinaria. Cf. Congregatio Plenaria..., p. 106.
}

${ }^{103}$ Cf. Congregatio Plenaria..., p. 265-267.

${ }^{104}$ Cf. Congregatio Plenaria..., p. 267.

${ }^{105}$ Cf. Congregatio Plenaria..., p. 268. En efecto el Código de Cánones de las Iglesias Orientales que se promulgaría el 18 de octubre de 1990 reproduce en su c. 1368 casí literalmente el texto del c. 1682 del Código de 1983: "1. Sententia, quae matrimonii nullitatem primum declaraverit, una cum appellationibus, si quae sunt, et ceteris actis iudicialibus intra viginti dies ab intimatione sententiae computandos ad tribunal appellationis ex officio mittatur. 2. Si sentencia pro matrimonii nullitate lata est in primo gradu iudicii, tribunal appellationis perpensis animadversionibus defensoris vinculi et, 
A continuación intervino el cardenal español Narciso Jubany que, tras expresar el sentido de su voto, afirmativo a la primera cuestión y negativo a la segunda, se refirió al problema que supuso el fenómeno que se conoció como "fuga de causas", sobre todo porque significó para los Tribunales españoles una auténtica lacra ante la opinión pública ${ }^{106}$. Destacó Jubany, sin embargo no olvidar la necesidad de establecer un control sobre los tribunales eclesiásticos, como habían sugerido los obispos norteamericanos.

El Cardenal König, se pronunció, sin embargo, en sentido diferente. Este prelado estimaba que cuando la sentencia había sido otorgada por un tribunal colegiado la apelación debía decidirla el defensor del vínculo según le dictase su conciencia ${ }^{107}$.

Quienes tomaron después la palabra, los monseñores Bank y Mons. Henriquez, expresaron su voto afirmativo ante la primera cuestión y negativo con respecto a la segunda ${ }^{108}$. El Cardenal Willebrands se manifestó en diferente sentido $\mathrm{y}$, atendiendo a lo que denominó necesidad de una "solución pastoral", que evitara la dilación innecesaria de las causas matrimoniales, entendía que sólo se debería procederse a la revisión de la sentencia cuando las partes privadas o el defensor del vínculo decidieran apelarla ${ }^{109}$.

Tras la intervención final del Cardenal Felici, en la votación 46 de los 59 asistentes se manifestaron a favor de exigir siempre la revisión de las sentencias que declaran la nulidad de un matrimonio ${ }^{110}$. A pesar de que no se cambió la decisión ya adoptada quienes habían manifestado su postura disconforme, mantuvieron sus proposiciones particulares ${ }^{111}$.

quae sint, etiam partium suo decreto vel decisiones continenter confirmet vel causam ad ordinarium examen secundi gradus iudicii admittat". Dada esta coincidencia he omitido un estudio particular de la confirmación abreviada en la legislación oriental.
${ }^{106}$ Cf. Congregatio Plenaria..., p. 268-270.
${ }^{107}$ Cf. Congregatio Plenaria..., p. 270.
${ }^{108}$ Cf. Congregatio Plenaria..., p. 270-272.
${ }^{109}$ Cf. Congregatio Plenaria..., p. 272-273.
${ }^{110}$ Cf. Congregatio Plenaria..., p. 274.
${ }^{111}$ Cf. Congregatio Plenaria..., p. 274-278. 


\section{Conclusiones}

Esta de la confirmación obligatoria de todas las sentencias declarativas de nulidad matrimonial fue una de las cuestiones más controvertidas en el debate inmediatamente anterior a la promulgación del Código de Derecho Canónico que tendría lugar en enero de 1983. Resulta cuanto menos curioso comprobar que los dos argumentos más importantes que se sostenían entonces son los mismos sobre los que los autores se pronuncian hoy. En efecto, existe cierto "miedo" a que se produzca una "avalancha" de causas de nulidad o con más precisión, un temor a que muchas personas pudieran pasar a un segundo matrimonio canónico si finalmente sólo una sentencia declarativa de nulidad fuera suficiente para hacerlo. Es el razonamiento que subyace a las críticas a los efectos del Procedimiento experimental norteamericano y que desde la propia Conferencia episcopal de los EEUU se trató de justificar en los debates de octubre de 1981. Si pensamos en el gran número de sentencias declarativas de nulidad que esperan ser confirmadas por los tribunales de apelación en España, es lógico esperar que se diera una situación parecida ahora en nuestro país de revocarse la obligación de la doble conforme.

Por otra parte, la protección del vínculo matrimonial es una segunda causa que se alega para mantener en cualquier caso la necesidad de la confirmación de la sentencia que declara la nulidad matrimonial. Pero esa interpretación tan amplia del principio favor matrimonii se contradice con el favor veritatis que también ha de ser tenido en cuenta para las causas matrimoniales. Sin duda el intento de conciliación entre los cónyuges cuando estos solicitan la nulidad de su matrimonio es una aplicación clara y deseable de ese principio pero, cuando ya se ha producido una primera declaración de nulidad y por consiguiente se ha pasado ya por todo un proceso judicial, el favor matrimonii no se ve directamente protegido por ese proceso de confirmación, más bien se "protege" el propio proceso de primera instancia. Confiar en el Defensor del Vínculo como garante de la validez del matrimonio parece una consecuencia lógica, y sin embargo hoy, al igual que se planteaba en 1981, parece algo difícil de conseguir en la práctica y ello por razones que poco responden al papel que se le adjudica en el proceso pues lo que se aduce es la dificultad que supone, para una persona que el fin y al cabo es miembro del tribunal, el impugnar la decisión de sus colegas. Ciertamente si ponemos en una balanza este prejuicio frente al tiempo y el gasto que supone contemplar siempre una segunda instancia, 
aunque sea "abreviada", habría que pensar hasta que punto hay equidad en la solución adoptada.

\section{Bibliography}

Congregatio Plenaria Diebus 20-29 Octobris 1981 habita en "Acta et documenta Pontificiae Commissionis Codicis Iuris Canonici Recognoscendo", Roma 1991.

D’Ostillo, F., La storia del nouvo codice di Diritto canonico, Ciudad del Vaticano 1983.

Gómez-Iglesias, C. V., La Pontificia Commissio Codici Iuris canonici recognoscendo en los años del Concilio Ecuménico Vaticano II: el plan de revisión de las leyes de la Iglesia, en "IC" XLII (2002), p. 109-133.

López Zubillaga, J. L., La doble decisión conforme en el proceso canónico Salamanca 2002.

Ochoa J., Cuestiones procesales "de iure condendo" en materia procesal en "Curso de Derecho matrimonial y procesal canónico para profesionales del foro" vol. 3 (Salamanca 1978).

Peña C., Derecho a una justicia eclesial rápida: sugerencias de iure condendo para agilizar los proceso canónicos de nulidad, en REDC 67 (2010), p. 741-771.

Ugge B., La fase preliminarelabbreviata del proceso di nullità del matrimonio in secondo grado di giudizio a norma del can. 1682, 2, Roma 2003. 